\title{
Disclosure and perceptions of social support in male victims of child sexual abuse
}

\author{
Abigail Leslie \\ West Virginia University
}

Follow this and additional works at: https://researchrepository.wvu.edu/etd

\section{Recommended Citation}

Leslie, Abigail, "Disclosure and perceptions of social support in male victims of child sexual abuse" (2014). Graduate Theses, Dissertations, and Problem Reports. 462.

https://researchrepository.wvu.edu/etd/462

This Dissertation is protected by copyright and/or related rights. It has been brought to you by the The Research Repository @ WVU with permission from the rights-holder(s). You are free to use this Dissertation in any way that is permitted by the copyright and related rights legislation that applies to your use. For other uses you must obtain permission from the rights-holder(s) directly, unless additional rights are indicated by a Creative Commons license in the record and/ or on the work itself. This Dissertation has been accepted for inclusion in WVU Graduate Theses, Dissertations, and Problem Reports collection by an authorized administrator of The Research Repository @ WVU.

For more information, please contact researchrepository@mail.wvu.edu. 


\title{
DISCLOSURE AND PERCEPTIONS OF SOCIAL SUPPORT IN MALE VICTIMS OF CHILD SEXUAL ABUSE
}

\author{
ABIGAIL LESLIE \\ Dissertation submitted to the College of Education and Human Services \\ at West Virginia University in partial fulfillment of the requirements \\ for the degree of \\ Doctor of Philosophy \\ in \\ Counseling Psychology \\ Department of Counseling, Rehabilitation Counseling and Counseling Psychology \\ James Bartee, Ph.D., Chair \\ Jennifer Adams, Ph.D. \\ Laura Capage, Ph.D. \\ Jeffrey Daniels, Ph.D. \\ Monica Leppma, Ph.D.
}

May 2014

Morgantown, West Virginia

(C) Copyright 2014

Abigail Leslie

All Rights Reserved 


\begin{abstract}
Disclosure and Perceptions of Social Support in Male Victims of Child Sexual Abuse
\end{abstract}

\begin{abstract}
Abigail Leslie
Child sexual abuse of males is a serious issue that is largely hidden in the United States because many victims never disclose the abuse. The literature review highlights the prevalence and severity of child sexual abuse of males and the negative effects nondisclosure has on the psychological well-being of the victim. The need to study factors affecting whether or not a male victim discloses is stressed, and social support is proposed to be an influencing factor. This study explored the impact of social support on disclosure status for male victims of child sexual abuse in parts of West Virginia and Ohio. It was predicted that higher levels of perceived social support would be positively related to disclosure and be negatively related to non-disclosure. Unfortunately, a small sample size was obtained due to time and geographical constraints, which prevented the intended data analyses of logistical regression to be completed. No statistically significant data regarding the relationship of perceived social support to disclosure was obtained from the analyses that were performed. Despite the shortcomings of the research, this research demonstrated that, by using Child Advocacy Centers, it is possible to conduct research solely on male victims of CSA at or around the time they were victimized, while being able to control for participant safety and control, anonymity, and the recollection of information about the abuse and disclosure status. The information gathered warrants further investigation of the relationship of perceived social support to disclosure status as the males in the study that disclosed abuse perceived higher amounts of social support in all categories than males who did not disclose. The information gathered also warrants further investigation of the relationship between socioeconomic status and disclosure status. Future research should attempt to recruit participants from several different CACs in several different regions of the country and plan to collect data for a longer time period.
\end{abstract}




\section{DEDICATION}

This dissertation is dedicated to my mom and dad. Your love, support, and encouragement throughout this whole process kept me going. Thank you for believing in me. I love you both. 


\section{ACKNOWLEDGEMENTS}

I want to express my gratitude to my Chair, Dr. James Bartee. From the very start you saw the value in this research. I cannot begin to thank you enough for sticking with me throughout this entire process. Your encouragement and belief in me kept me going. I think, at times, you believed in me more than I believed in myself. Your knowledge, personal examples, suggestions, edits, etc. helped improve my writing and my study, and have just helped me develop into the professional I am today, which is a person I am incredibly proud of. I am lucky to have had the opportunity to learn from you over the last several years. Thank you. To my other committee members, Dr. Capage, Dr. Adams, Dr. Daniels, and Dr. Leppma, your support has meant the world to me. Dr. Capage, you were the first person to open my eyes to this important topic, which ultimately has led me to find my passion and my niche in the psychology world. Thank you for providing me with amazing opportunities and the chance to learn from you at your center. Dr. Adams, I am not quite sure what I would have done without you along for this journey. You have always been there for me professionally and as a friend, especially through some of the toughest times of my life while in the master's program. My spirits were always lifted around you and I could always count on you for a good laugh! Dr. Daniels, I appreciate you taking the time to be a part of my committee among all of your other million obligations in the program. Your feedback was always helpful. I think I learned the most from you when I listened to you talk about your current research project involving hostage taking. Your passion and excitement are inspiring! And finally, Dr. Leppma, without you, there would be no committee. Thank you for your willingness to be a 
member of my committee and for directing me to your friend's awesome study. I enjoyed getting to know you and wish you all the best!

An important thank you goes to the four Child Advocacy Centers that made themselves available for me to recruit participants. Without your help this study would not have been possible. And of course, a huge thank you goes out to the brave young men who chose to help me learn more about their perceptions and experiences. You have helped build the path that will lead to preventing child sexual abuse.

To my loved ones - Mom, Dad, Chris- you have put up with a lot! Thank you for sticking with me through this and cheering me on to the finish. Seeing how proud you all are of me for making it to the end made this whole thing worth it!

Last, and certainly not least, I thank Dr. Amy Wilson Strange. You began as my professor, became my supervisor, served as my mentor, and ended as my colleague and most importantly, my friend. Without you, I would have never ended up in this doctoral program. Your belief in me and my abilities gave me the confidence to pursue this degree and keep going every time I wanted to quit. The experiences you provided me and the example you set for me are more than I could have ever asked for. I cannot imagine a better person to serve as the model of the professional I aspire to be. More than ever I realize what a blessing you have been in my life and I hope to pay it forward and one day be that blessing for someone else in this field. From the bottom of my heart, thank you. 
TABLE OF CONTENTS

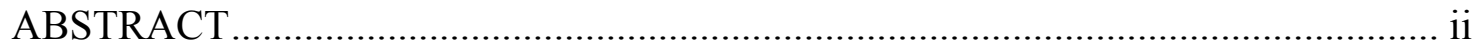

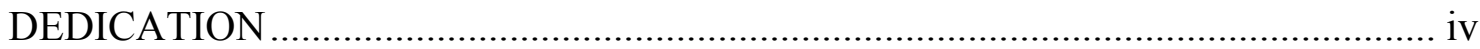

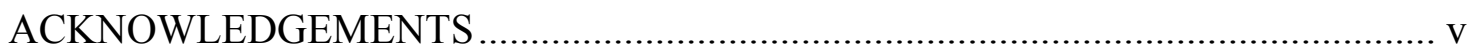

CHAPTER ONE: INTRODUCTION \& REVIEW OF LITERATURE ........................ 1

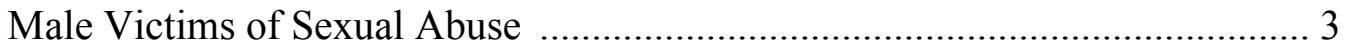

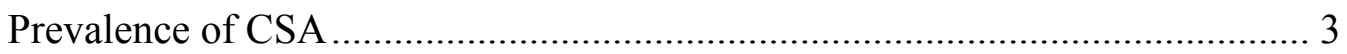

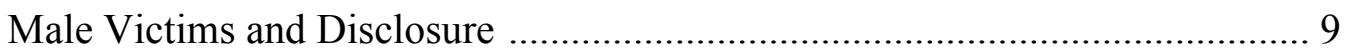

Characteristics of Abuse ..................................................................................... 11

Factors Affecting Disclosure ………………………………………….......... 16

Perceiving Others: Factors Affecting Disclosure …………………………..... 21

Types of Disclosure ..................................................................................... 28

Social Support ......................................................................................... 29

Social Support in the Lives of Children and Adolescents ................................. 32

Implications for Future Research................................................................... 41

Importance of Supportive Non-Parental Adults ................................................ 42

Social Support and Disclosure …………….................................................. 47

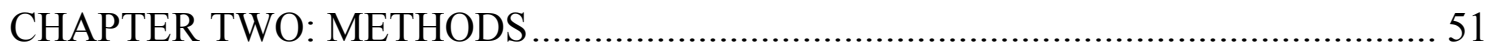

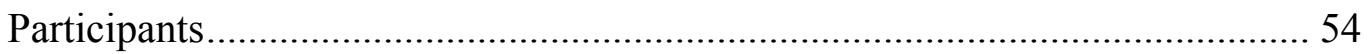

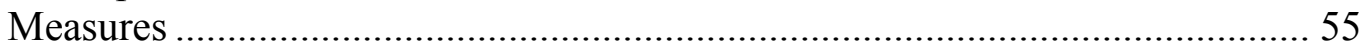

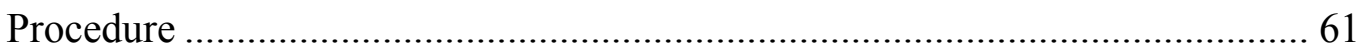

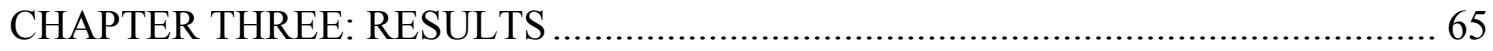

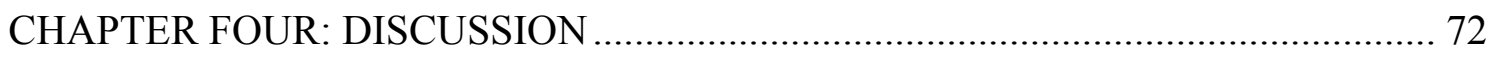

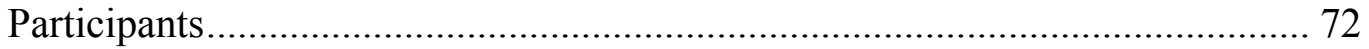

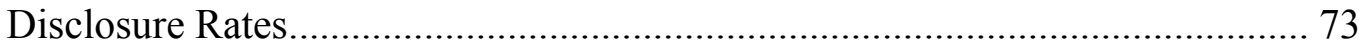

Demographic Variables Affecting Disclosure Status ......................................... 74

Perceptions of Social Support and Disclosure ..................................................... 76

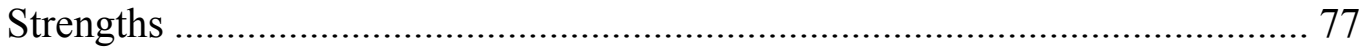

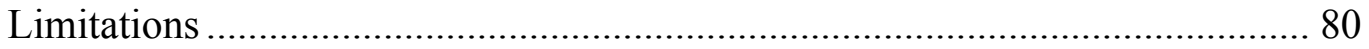

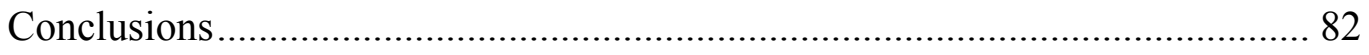

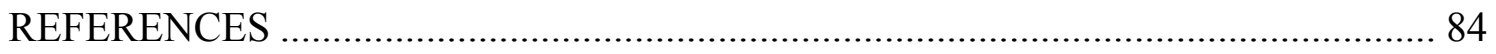

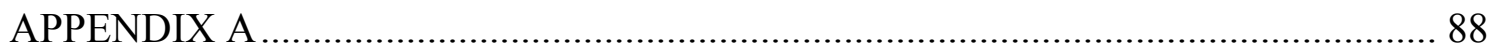




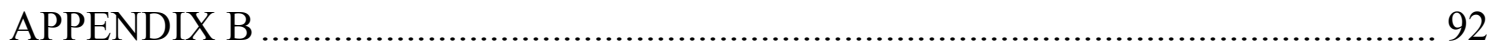

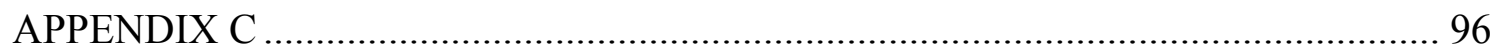

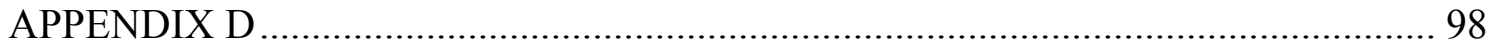

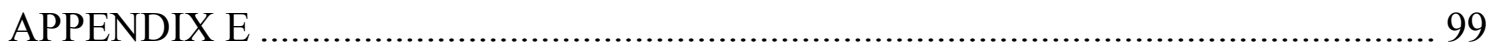

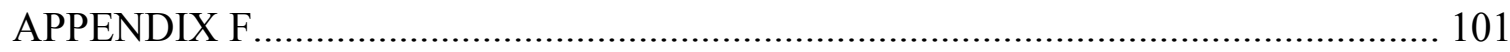

\section{LIST OF TABLES}

Table 3.1 Intercorrelations with the Sample Among the Categories of the CASSS...... 68

Table 3.2 Comparison of the Means of the Category Scores on the CASSS Between Participants Who Disclosed and Did Not Disclose Abuse........................... 69

Table 3.3 Relationship Between Household Income at the Time of Abuse and Disclosure Status.......................................................................... 71

Table 3.4 Relationship Between The Relationship of the Abuser to the Victim and Disclosure status. 


\section{CHAPTER ONE:}

\section{BACKGROUND AND}

\section{REVIEW OF THE SELECTED LITERATURE}

Sexual abuse of children (CSA) is a serious issue in the United States. Thus far, the focus of the majority of research conducted on victims of sexual abuse has focused on female survivors, even though it is estimated that at least $16 \%$ of male children have been sexually abused (Sorsoli, Kia-Keating, \& Grossman, 2008). In fact, less than 15 published studies on male victims of child sexual abuse exist. Not only is there a lack of availability of information on male CSA victims, but also the research that has been done has not yielded much useful information. The data collection procedures have often been flawed because often authors utilized assessments whose psychometric properties had not been established, and the terms used to define abuse and disclosure that have been used by the authors are vague and imprecise, leaving the reader unable to draw any meaningful conclusions regarding the greater population of male victims of CSA.

Based on their research, Garnefski and Arends (1998) suggest that males experience a greater severity of symptoms than females following sexual abuse. In fact, male sexual abuse survivors are more likely than female sexual abuse survivors to be aggressive and engage in criminal behavior, drug use, and alcohol use. They are also more likely to have truancy issues in school and attempt suicide more frequently (Garnefski \& Arends, 1998). Often, male victims of CSA become juvenile sexual offenders themselves (Brannon \& Larson, 1991). 
Despite the fact that males may experience a greater severity of symptoms than females, research findings indicate that male victims underreport sexual abuse. Even when the male CSA victims report the abuse, some males indicate that a significant amount of time had elapsed from initial onset of abuse to disclosing the sexual abuse. Often, male CSA victims do not disclose the sexual abuse until well into their adult years. Anonymous surveys reveal that some males who were CSA victims have never disclosed the abuse (Sorsoli et al., 2008, Tang, Freyd, \& Wang, 2007).

Disclosure of sexual abuse by the child victim is the most significant way by which child sexual abuse is uncovered (Lippert, Cross, Jones, \& Walsh, 2009). The act of disclosure of sexual abuse is a critical factor in ensuring a victim receives treatment, early intervention, and support (Sorsoli et al., 2008). A better understanding of the disclosure process of male sexual abuse victims and the factors affecting whether or not a victim decides to disclose is imperative to the victims' recovery. Gaining an understanding of disclosure may lead to helping males disclose sexual abuse and receive the treatment that is needed. Disclosure of child sexual abuse may prevent future abuse from occurring. It may also contribute to prevention so that other children will not be sexually abused by the same perpetrator as law enforcement can investigate and apprehend those individuals responsible for the abuse. Likewise, if a male child discloses abuse, and he is protected and supported by adults, given the opportunity to receive therapy, and the perpetrator is convicted; this may increase the likelihood that other male children who are also victims of abuse will disclose the abuse as well. To increase the likelihood of disclosure of sexual abuse by male children, factors related to disclosure must be identified. 


\section{Male Victims of Sexual Abuse}

Sexual abuse is a specific form of abuse in which a child can be a victim. The perpetrators of child sexual abuse can be adults or even children at least five years older than the victim. Often times the perpetrator is someone whom the child knows and trusts, such as a parent, sibling, grandparent or neighbor; although, some perpetrators are strangers to the child victim. Most often, sexual abuse of a child comes in the form of bodily contact between the victim and the perpetrator. This bodily contact can be in the form of digital penetration, penile penetration, oral sex, or rubbing of private parts. Either the perpetrator or the victim can be the one engaging in the act, and often the acts are reciprocated. Exposing genitals to a child and using a child for pornography are also considered sexual abuse (Medline, 2009). Child victims are often tricked, seduced, or manipulated into sexual abuse scenarios, and often times the children are forced into these scenarios by threats of violence or actual violence at the hands of the perpetrator (Brannon \& Larson, 1991).

\section{Prevalence of CSA}

It is estimated that 39 million survivors of child sexual abuse are living in America today. Out of all the cases of reported sexual abuse, $70 \%$ involved children and adolescents under the age of 17 ("Darkness to Light", 2009). Until recently, not much attention has been given to males, despite the fact that at least $16 \%$ have been victims of sexual abuse (Sorsoli et al., 2008). Some research results indicate that the percentage of male CSA victims is higher in clinical and treatment settings (Petronio, Reeder, Hecht, \& Ros-Mendosa, 1996). This may be due to the fact that in clinical and treatment settings 
intake paperwork and questionnaires screen for history of abuse and many survivors of abuse choose not to disclose abuse without being prompted (Petronio et al., 1996).

Studies that have included males have not revealed much gender-specific information, as males only accounted for a small number of the total sample size. Due to the underrepresentation of males, few results have been found from studies utilizing both male and female victims of CSA (e.g., Ullman, 2007) that can be generalized to male victims. Likewise, studies using female CSA victims cannot be generalized to male CSA victims, as it is unknown as to whether males' experience of abuse is the same as females.

Recently, to gain a better understanding of their experiences, more studies have been conducted on male victims of CSA. For instance a study was done comparing male and female victims of CSA. The results of this study revealed that males experience a greater severity of psychological symptoms than females (Sorsoli et al., 2008). An investigation by Reinhart in 1987 and one by Branson and Larson in 1991 both discovered that some male victims eventually became perpetrators of sexual abuse. In the study conducted by Branson and Larson (1991), 17.8\% of the male juveniles that were incarcerated for being perpetrators of sexual abuse admitted to being victims of sexual abuse themselves. According to Easton, Chooey, O'Leary, Zhang, and Hua (2011), other negative effects of CSA to males include substance abuse and suicidal thoughts and attempts. Also, these authors purport that a relationship between CSA and sexual maladjustment involving a preoccupation with sex, sexual risk-taking, and compulsive sexual behaviors can last into adulthood, especially if the abuse is not addressed. Reviews of research by Petronio and colleagues (1996) conclude that male 
victims of CSA who do not receive services are more susceptible to a number of problems including dissociative disorders, post-traumatic stress disorder (PTSD) and depression, as well as anxiety, feelings of helplessness and powerlessness, limited coping ability (Petronio et al., 1996), and difficulties in communication development, specifically in understanding the non-verbal behaviors and emotional expressions of others (Hecht et al., 1986).

Garnefski and Arends (1998) compared the emotional and behavioral problems and suicidality of male and female victims of child sexual abuse with those who have no history of abuse. Participants included 1490 secondary school students between the ages of 12 and 19 ( 745 with self-reported history of sexual abuse, 745 without) in the Netherlands. The participants filled out an extensive questionnaire measuring 11 primary emotional and behavioral problem areas. The questionnaire included such areas as loneliness, anxiety, criminal behavior, truancy, alcohol and drug use, and suicidality (Garnefski \& Arends, 1998).

Using multivariate analysis of variance (MANOVA) to compare the groups, Garnefski and Arends found that overall victims of sexual abuse were significantly more likely to experience behavioral and emotional problems than those that have not experienced sexual abuse. When comparing male and female victims of sexual abuse, males experienced significantly greater feelings of loneliness, and were more likely to use alcohol and drugs and engage in aggressive behavior and criminal behavior than females. Male sexual abuse victims were more likely to be truant than their female counterparts, and male victims reported significantly more suicide attempts than female victims (Garnefski \& Arends, 1998). 
Ullman (2007) used a retrospective study to review the effects of CSA on males and females. Participants were recruited from the psychology department subject pool and through announcements about the study in criminal justice classrooms. The participants completed the packets that addressed topics such as CSA experiences, disclosure, and psychological symptoms from inside the privacy of their own living spaces. CSA was defined as having an experience ranging from indecent exposure to private parts to completed penetration of genitals before the age of fourteen by someone at least five years older. In the survey, 15 questions regarding CSA experiences assessed attempted and completed forms of different types of sexual abuse on an ordinal scale ranging from no abuse to completed penetration. The characteristics of the abuse were obtained by items that included perpetrator identity, abuse duration, and degree of upset at the time it occurred. The degree of upset was rated on a 5 point Likert-type scale from not at all to very much. The participants were also asked whether or not they disclosed the abuse, if it was purposeful or accidental, whom they told, and the age at which they first disclosed. Timing of the disclosure was assessed by asking how long after the experience the disclosure occurred. Finally PTSD symptoms in response to the CSA were assessed by a 17-item brief self-report that corresponded to the criteria needed to meet a diagnosis of PTSD according to the DSM-IV-TR (Ullman, 2007).

Of those participants recruited for the study, 733 completed and returned the surveys, constituting a $92 \%$ return rate. Less than one-fourth of the sample reported CSA, with $13 \%$ of those reports coming from males. Based on the responses of both the males and females who participated in the study, most (76\%) reported the nature of the abuse was fondling, while $4.3 \%$ reported attempted penetration and $19 \%$ reported 
completed penetration. Of the perpetrators, $89 \%$ were known by the victims: $28.2 \%$ were neighbors, $38.7 \%$ were family members, 13.5 were characterized as friends, and just under $5 \%$ of the victims had multiple offenders. Disclosure was immediate and purposeful in $87.9 \%$ of the cases, meaning that the victims sought help and wanted a trusted person to know about the abuse; however, $63 \%$ reported that they waited one year or longer to report the abuse (U1lman, 2007).

A one-way analysis of variance (ANOVA) was utilized to compare CSA cases in which the perpetrator was a relative with those in which the perpetrator was an acquaintance or stranger. The cases were compared using chi-squared tests on the specific characteristics of the abuse, such as the identity of the perpetrator, the degree of emotional closeness to the perpetrator, degree of upset, and the abuse duration. Further, chi-squared tests were used to compare disclosure characteristics, such as whether or not a disclosure occurred, whether the disclosure was accidental or purposeful, and how long it took for the victim to disclose the abuse. Additional chi-squared tests were used to compare the cases on the presence of PTSD symptoms. Timing related to disclosure was found to differ, as those whose perpetrators were relatives took longer to disclose the abuse than those who were abused by perpetrators in the other categories; however, only the timing of disclosure between victims of abuse by relatives and victims of abuse by strangers differed significantly. Abuse by relatives was found to be significantly more severe than abuse by strangers or acquaintances and the duration of the abuse was significantly longer for cases involving relatives than for strangers and acquaintances. Those that were abused by relatives reported significantly more PTSD symptoms related 
to the abuse than those abused by non-relatives. Finally, those that delayed disclosure experienced more PTSD symptoms than those that told immediately (Ullman, 2007).

Even though males constituted a small percentage of the sample, the percentage of those who reported experiencing CSA is consistent with national statistics (Sorsoli et al., 2008). These results should be taken with caution as the author did not analyze the results according to gender, nor did she provide any information regarding the number of times the abuse occurred or how long it lasted. Also, the definition of CSA is limited as it only pertains to a certain age-range. Based on the results, CSA survivors victimized by relatives experienced more PTSD symptoms along with greater negative effects on ability to disclose the abuse promptly. Victims of family perpetrators experience more serious forms of actual abuse. The stress of withholding disclosure and being abused by a family member both appear to contribute to greater PTSD symptomatology; however, the author did not elaborate on the types of symptoms that were experienced and whether or not the victims reached requirements to meet an actual PTSD diagnosis. The results of this study are vague in that there was no elaboration on the details of PTSD symptoms experienced, nor were time frames for disclosure specified; however, the results provide evidence that the majority of victims of CSA do not disclose abuse promptly, and delayed disclosure is related to experiencing more symptoms of PTSD. These results are especially true when the perpetrator of the abuse is a family member.

Because male victims of child sexual abuse experience severe behavioral and emotional problems, even more so than their female counterparts, it is important that these victims receive help in addressing the negative psychological symptoms that have resulted from the abuse. Disclosure is the most significant way in which child sexual 
abuse is discovered (Lippert et al., 2009) and delayed disclosure is related to more severe effects of the abuse (Ullman, 2007). Studying the disclosure process of male victims is vital in helping them receive the services they need.

\section{Male Victims \& Disclosure}

Despite the fact that male victims of sexual abuse appear to suffer more intense negative psychological effects than female victims, they are less likely to disclose the abuse (O'Leary Barber, 2008, Priebe \& Svedin, 2008). Priebe and Svedin (2008) found that while $81 \%$ of female victims disclosed sexual abuse, only $69 \%$ of the males ever disclosed. Retrospective reports show lower rates of disclosure, indicating significant underreporting of CSA (O'Leary \& Barber, 2008). Some males delayed disclosure for five years or more after the initial onset of abuse, while others never told about the abuse until adulthood. In fact, Sorsoli and colleagues (2008) found that many male victims did not disclose CSA until opportunities to participate in research regarding sexual abuse became available (Sorsoli et al., 2008). Other research shows that some males never tell (Priebe \& Svedin, 2008, Tang, Freyd, \& Wang, 2007). Review of the literature conducted on disclosure suggests that the rate of disclosure increases with age (O'Leary

$\&$ Barber, 2008). The most underreported cases, meaning those that were never disclosed in a timely manner, involve sexual victimization of young males (Brannon \& Larson, 1991).

London, Bruck, Ceci, and Shuman (2005) found similar results. In studying research already conducted on disclosure of CSA by males, London and colleagues found that roughly $75 \%$ of victims of child sexual abuse do not disclose within the first year. Also, $18 \%$ of victims waited more than five years to disclose the abuse (London et al., 
2005). Kogan (2005) examined the impact that disclosing child sexual abuse had on victims' symptomology and revictimization. Participants included 111 adolescents between the ages of 12 and 17 . The adolescents were first classified by disclosure. Prompt disclosures were those that occurred within one month of the initial onset of the abuse. Delayed disclosures were those that occurred after one month from the initial onset of the abuse, or not at all. Of the 111 participants, 36 (32\%) disclosed promptly, and $74(67 \%)$ had delayed disclosures (Kogan).

Kogan (2005) explored the association between disclosure variables and outcome variables (number of symptoms and revictimization) in both males and females. The results indicate that delayed disclosure was associated with the participant endorsing two or more negative symptoms, and prompt disclosure was related to having no symptoms. Also prompt disclosure was significantly associated with having less chance of revictimization (Kogan, 2005). Although the author did not explore these results further, a plausible explanation for this finding might be that prompt disclosure by the child victim led to receiving support and protection from safe, healthy adults. It is likely that disclosure of sexual abuse led to the involvement of child protective services and law enforcement, which kept the perpetrator away from the child. Also, victims of CSA who disclose often receive therapeutic services to recover from the abuse and part of therapy is likely body safety education and developing a safety plan to prevent further victimization (Cohen \& Mannarino, 1998). Therapy also would attend to both internal and external symptom remediation.

The results of Kogan's (2005) study have serious implications. First, most victims of child sexual abuse delay disclosure or never disclose the abuse, at least in 
adolescence. This causes these victims to be more susceptible to negative psychological symptoms and less likely to have these symptoms ameliorated. Second, and more importantly, the delay in disclosure exposes these victims to a greater chance of being revictimized. If the child does not disclose the abuse, then no one is able to support and protect the child, which leaves him vulnerable to further abuse.

\section{Characteristics of Abuse}

Lab and Moore (2005) sought to investigate the extent of CSA and characteristics of the abuse in a sample of men receiving psychiatric inpatient services in the United Kingdom. The authors screened out male patients who could not speak English fluently, those whose ability to hold a rational conversation was impeded by a thought disorder, and those with extreme emotional distress. Participants were provided information regarding the purpose of the study, the procedure, issues regarding confidentiality and a list of services such as help lines for sexually abused men. The authors collected age, ethnic background, and primary diagnosis data from medical records (Lab \& Moore, 2005).

Participants engaged in a structured interview regarding childhood sexual abuse. Sexual abuse was defined as any sexual contact between a child of 13 years or younger with another person who was at least five years older, or a family member who was at least two years older. Those who had been sexually abused were asked to elaborate on the characteristics of the abuse with regard to duration and frequency, the relationship between the victim and the perpetrator, and whether or not force was used. The amount of distress the abuse caused was rated by the participants on a Likert-type scale ranging 
from no distress to unbearable distress, and they were asked about whether they viewed the event as sexual abuse or not (Lab \& Moore, 2005).

The results reported by the authors were descriptive in nature. No statistical analyses were performed. Of the 74 participants, $43 \%$ were White, $41 \%$ were Black AfroCaribbean, 9\% were Black African-American and 3\% fell into the "other" category. The participants ranged in age from 18 to 66 with a mean age of 37 . According to the authors, $31 \%$ of the participants reported sexual abuse; however, only $22 \%$ of those who reported abuse actually had it documented in their medical records. Over half (52\%) of those that reported abuse in the interview stated that they never disclosed the abuse prior to that point in time. Finally, of those that reported abuse, $35 \%$ stated that they believed the incidents they described were not sexual abuse. Of those that were abused, 83 reportedly were abused by other males, $61 \%$ reportedly were abused by a family member, and 39\% stated they were also abused by a female, indicating that some were abused by more than one perpetrator. The most common form of sexual abuse reported was fondling another's genitals or being fondled on the genitals by a perpetrator. The mean age at onset of the abuse was nine years old and the mean age of the perpetrator was 23 years old. Force, threats, and bribes were used as coercion methods with force and threat of harm being most common. Finally, two thirds of those abused rated the incident from mild to unbearable distress, with one third rating the event as causing no distress (Lab \& Moore, 2005).

Unfortunately, descriptive data do not allow many conclusions to be made and leave much room for speculation by the reader. Based on personal speculation, for the participants rating the incidents as causing no distress, it could have been that that the 
perpetrator was a female and the male did not view the sexual act as abuse. It is possible, according to Mendel (1995) based on male stereotypical roles, which support the idea that males cannot be victims of sexual abuse, that these male CSA victims believed that this act was something that was "supposed to happen" and was "normal" because males should have sex with females. Further, these participants may not have seen themselves as victims regardless of the gender of the perpetrator. They may not even have viewed a sexual encounter with a perpetrator of the same sex as abuse. It is possible that male victims whose perpetrators were also male may have been more concerned that they were homosexual, because of a sexual encounter with another male, and never realized that they were victims of abuse (Mendel, 1995). Unfortunately, further investigation of these findings was not conducted and the reader is left only to speculate with no data to support conclusions.

It is unknown whether the rates of disclosure or actual occurrence of reported abuse differed by ethnic background or age. Nor is it known if ethnic background had an impact on whether or not the sexual acts were considered abuse by the participants. The definition of sexual abuse used in this study is a limitation as it is conservative and may have limited the number of disclosures that occurred. Finally, as with any self-report data, the conclusions should be taken with caution as it is unknown how accurately the narrative descriptions reflect historical events.

Despite the limitations, this study was valuable in that the results alluded to prevalence rates of CSA in psychiatric inpatient populations, and provided evidence that the majority of males sexually abused as children do not disclose the abuse at or near the time of its occurrence. The study also showed that in the majority of cases the experience 
of the abuse was negative and in some instances the distress was considered unbearable. The majority of the instances disclosed by the participants had characteristics shown to be associated with poorer recovery outcomes such as multiple perpetrators, use of threats, and younger age at the onset of abuse.

According to Brannon and Larson (1991), being a victim of CSA and not disclosing the abuse denies one the ability to receive the help that is needed, which increases one's risk of becoming a juvenile offender. The authors based their findings on previous research on male juvenile offenders (Groth \& Longo, 1982). According to the results of their research, being a victim of sexual abuse can create a feeling of loss of control for the victim. The victim may not regain a sense of control without disclosing the abuse and thus receiving needed psychological services. This in turn could lead these victims to attempt to regain the feeling of control by sexually offending others (Groth \& Longo, 1982).

To gain more insight into the childhood victimization of juvenile offenders, Brannon and Larson (1991) investigated adjudicated male juvenile sexual offenders in a western state's institutional group treatment facility $(n=123)$. The participants were part of a peer counseling program in an institution that emphasized individual honesty, acceptance of personal responsibility, empathy and interpersonal openness, individual group problem solving, and high levels of community service oriented activities. The researchers conducted interviews with the participants at two points in time during the duration of the group. They gathered information on history of any sexual abuse, the age the assault occurred, and the nature and perpetrator of the assault was gathered. The sexual victimization of the participants was divided into two categories: molestation and 
abuse. The authors defined molestation as being "tricked, seduced, or manipulated into sexual relations without being intimidated by threats or physical coercion" (p. 325) and abuse as being forced into sexual relations where force occurred via verbal threats, intimidation or physical abuse and violence. Also the participants were asked if they disclosed the abuse prior to the interview, if they currently acknowledged the abuse within the group, and the group intervention that was most influential to the disclosure (Brannon \& Larson, 1991).

Utilizing a 31\% expected victimization rate, which was derived from earlier research, the data obtained in this study were analyzed using chi-square techniques. Descriptive statistics on those data were also obtained. Ages of the participants ranged from 14 to 19 years old with a mean age of 16.1 years. Based on the Chi-square goodness of fit, the early childhood sexual victimization rates of juvenile offenders varied significantly from those among a "normal" population, indicating that CSA occurs more frequently in juvenile offenders. Molestation was the form of abuse most frequently encountered as it was disclosed by $54.4 \%$ of the participants. However, with regard to severity, only $16.4 \%$ of those that were molested reported incidents involving simple touching or fondling. Most incidents involved heterosexual intercourse and fellatio. The mean age of participants disclosing molestation was 9.3 years with the initial age of onset of CSA ranging from three to 16 years old. Of the participants $36.3 \%$ reported being victims of abuse. The mean age of onset was nine years old with a range of onset from four to 16 years old. Of those disclosing abuse at the time of the interview, only $30 \%$ reported that they disclosed the details of the incidents prior to entering the peer group treatment program. Breaking that statistic down by categories, only $26.8 \%$ of those 
molested and $40.9 \%$ of those that were abused disclosed the abuse prior to the group program (Brannon \& Larson, 1991).

Based on the results, $90.7 \%$ of the sexual offenders that participated were victims of CSA and $70 \%$ never disclosed the abuse. Based on this study, there are indications that sexual offending by males is associated with being sexually abused as a child and that the majority of sexual offenders never disclose the abuse. It is unknown whether the offenders in this study received mental health services prior to entering the treatment program, but there is indication that the negative effects of the CSA that were incurred were never fully addressed. Further research is needed to assess the accuracy of these indications.

It appears that the majority of male victims of CSA do not disclose the abuse. Those that do disclose often delay their disclosure. By not disclosing abuse immediately these male victims are denying themselves the help they need. Male victims of CSA, by not disclosing abuse, are subjecting themselves to the possibility of further victimization as well as the likelihood of experiencing more intense psychological, emotional, and behavioral difficulties. There is even a chance that they will become sexual offenders themselves. It is important to understand what is hindering male victims from disclosing sexual abuse and thus receiving the help and relief they need.

\section{Factors Affecting Disclosure}

A review of the literature shows that few studies have analyzed other variables besides disclosure rates and effects related to the act of disclosing CSA. Most of the pertinent research examining barriers to disclosure for CSA victims has been conducted outside of the United States (e.g., Crisma et al., 2004 and Teram et al., 2006). Although 
the results from these studies cannot be directly generalized to children victims from the United States, the findings can guide future research on U.S. children. The results can also provide insight regarding the personal internal and external processes of child victims of sexual abuse in the U.S.

As part of a longitudinal study, Nagel, Putnam, Noll and Trickett (1997) sought to find demographic factors that influenced the disclosure process of 68 female victims of child sexual abuse between the ages of six and sixteen. The participants were referred by a child protective service agency near Washington, D.C. The researchers interviewed both the victims and their caregivers. The results indicated that demographics such as race, socioeconomic status, parents' occupation and parents' education were not influential in the disclosure process. After controlling for age of the victim, it was found that cognitive functioning was also not related to whether or not a victim disclosed. These results support the previously mentioned studies that found no impact relative to disclosure based on demographic variables and cognitive functioning (Nagel et al., 1997). Although these studies did not yield any significant findings, the results are still important. The results suggest that researchers may be able to rule out demographic variables as having an influence on disclosure, at least in females. This study needs to be replicated with males. If confirmed in males, the focus would be able to shift to other factors that may affect disclosure such as the age of the victim and social influences within the victim's life.

To examine the effect of age on disclosure, London, Bruck, Ceci, and Shuman (2005) reviewed 16 articles written since 1990 that contained statistics on the frequency of disclosures by male and female victims. Age-disclosure associations were examined, 
and the results suggested that rates of disclosure are dependent upon age. Specifically, it was found that school-aged children were more likely to disclose than pre-school aged children, and that children in general were more likely to disclose after the age of four. Also, when examining disclosure rates of children in foster care, the older the child was, the more likely he or she would disclose during the first therapy session. The younger the child, the more likely it would take two or more sessions to disclose abuse (London et al., 2005).

This study is important because it provides insight into a factor affecting disclosure in child victims of sexual abuse. It appears that the older a child is, the more likely that child is to disclose abuse (London et al., 2005). This is understandable considering developmental factors that affect a child's ability to elaborate on events and utilize memory. The older a child becomes the more able he or she is to recall events and elaborate the details (Erikson, 1950/1963). Due to these findings, the focus of research is able to shift to understanding psychological influences that affect the disclosure of sexual abuse.

Crisma et al. (2004) interviewed young people in Italy who had reportedly been sexually abused as a child. The goal of the research was to understand what factors impeded disclosure from the victim's perspective. Crisma et al. found that the participants rarely disclosed the abuse spontaneously. At least $30 \%$ reported that they never disclosed the abuse because they felt they could not rely on family members for support. The majority of the participants also indicated that embarrassment and selfblame kept them from disclosing the abuse (Crisma et al.). 
Although these results are primarily based on female victims living in Italy, it still provides insight into the experiences of victims of sexual abuse. In fact, similar studies in the United States with male victims occupying a much larger percentage of the sample found similar results. It appears that embarrassment and self-blame are key features that prevent children, both male and female, from disclosing sexual abuse (Kogan, 2005; O’Leary \& Barber, 2008; Priebe \& Svedin, 2008). Also, victims that did not disclose child sexual abuse were more likely to view their parents as less caring and less protective than those that did disclose (Priebe \& Svedin, 2008).

Sorsoli, Kia-Keating, and Grossman (2008) conducted qualitative research focusing solely on adult male victims of child sexual abuse in order to gain a better understanding of men's experiences regarding disclosure. Sixteen men were recruited in a medium-sized city by flyers seeking men with histories of child sexual abuse. These men completed two semi-structured interviews related to the experience of CSA. According to the information provided by the participants, only one male from the 16 participants that were interviewed purposefully disclosed the abuse; however, his disclosure was met with disbelief and shame, and he never attempted to disclose the abuse again. Several other participants reported disclosing small elements of abuse, and some reported never disclosing the abuse until adulthood (Sorsoli et al., 2008).

After transcribing and coding the interviews, Sorsoli and colleagues were able to identify three domains in which barriers to disclosure exist for male victims: personal, relational, and sociocultural. Personal barriers included emotional readiness, safety, shame and worry about potential blame. Relational barriers were identified as fears of isolation or general relationship difficulties, and lack of support. Barriers identified in 
the sociocultural domain include the belief that it was unacceptable for men to experience victimization and if they had, it was never to be discussed (Sorsoli et al., 2008).

Other studies revealed similar results. O’Leary and Barber (2008) and Kogan (2005) found that negative attitudes toward male victims by peers and professionals thwarted disclosure. O’Leary and Barber also found that a victim's experience of confusion regarding thoughts and emotions related to the abuse hindered the disclosure process. Also, fear of negative reactions (Ullman \& Filipas, 2001), and fear of not being believed (Nagel et al., 1997) were other factors found to hinder disclosure.

To achieve a better understanding of the experiences of male victims of CSA and their perceptions of health professionals, Teram, Stalker, Hovery, Schachter and Lasiuk (2006) investigated male and female survivors of CSA in Canada. The study included interviews of 49 male and 46 female survivors of CSA who were at least 18 years old, spoke English, and consented to talking about their encounters with health care providers. The participants were recruited through posters distributed to health professionals and agencies known to provide counseling and support for survivors of CSA. The interviews took place in six Canadian provinces in a myriad of settings: researchers' offices, primary health care clinics, and offices providing services to male survivors. The interviews were semi-structured and guided by a focus on two main issues: participants' experiences with healthcare professionals who do not have specific training in mental health and the participants' thoughts about healthcare practices that would be sensitive to their needs. All interviews were audiotaped, transcribed, and analyzed using the constant comparative method. Also, once transcribed and coded, the participants were provided the opportunity to review the transcriptions and to offer comments, clarifications and 
corrections to the researchers. Major themes were extracted from the interviews and four focus groups consisting of the participants and healthcare providers met to discuss and elaborate on the themes. The focus groups consisted of female survivors and nurses, female survivors and physicians, male survivors and nurses, and male survivors and physicians (Teram et al., 2006).

\section{Perceiving Others: Factors Affecting Disclosure}

Based on the results of the research study by Teram and colleagues (2006), the participants perceived differences in reactions to sexual abuse based on gender. It was asserted by both genders that health professionals are perceived as being skeptical about men who disclose sexual abuse and tend to take male disclosures less seriously than females. They expressed the belief that these differential reactions to survivors based on gender shaped their help-seeking behaviors. The difficulty to accept males as victims was a factor that the male participants reported as a hindrance to reporting the abuse. When recalling experiences in clinical settings, many males in the study reported that they were never asked if their emotional or behavioral issues that brought them into therapy were the result of being sexually abused. In fact, during focus groups, a physician expressed his belief that men are not victims of abuse, they abuse others, thus confirming the reluctance to accept males as victims. The participants also reported there was a perceived lack of concern of others regarding the sexual abuse of boys by older women. These male survivors reported being given the message through society that they were lucky to have been seduced by older women and they fulfilled every man's dream. For males, having sex with women is normalized and there is a widespread assumption in society that abusers are male and the victims are female. Following stereotypical roles, 
males are supposed to be masculine and females are supposed to be feminine, and the masculinity of males is questioned if they assume a victim role. These factors led to the assumption that healthcare professionals would have the same beliefs (Teram, et al., 2006).

The prevalence of homophobia was apparent throughout the study, as well. The male participants demonstrated perceptions that those from Western societies believe that male survivors who are abused by men are gay. Many also reported that their own sensitivities to being considered gay played a major role in their interactions with healthcare professionals and the experience of having sexual encounters with males led to struggles with their own sexual identity. Male survivors of CSA reported fear that health professionals would not be sensitive to these issues. Similar to the theme of homophobia were the themes that males are strong and not vulnerable, which arise from the masculine stereotype placed on males by society. For these participants, disclosing sexual abuse meant acknowledging weakness, vulnerability and the experience of unpleasant emotions, which were all perceived as being unacceptable by society because they do not coincide with the masculine stereotype, and led to the belief that health professionals would hold the same opinions as society as a whole (Teram, et al., 2006).

In the study previously mentioned by Brannon and Larson (1991) in which juvenile sexual offenders were interviewed regarding prior history of CSA, numerous offenders reported disclosing a history of CSA during the inpatient group. Those that disclosed the abuse were able to identify factors of the group that helped facilitate disclosure. The participants reported perceiving the group as being supportive and 
accepting and conveying an unconditional acceptance of the members. They also alluded to the feeling of individual self-worth (Brannon \& Larson, 1991).

Petronio, Reeder, Hecht, and Ros-Mendosa (1996) explored the types of rules and criteria that children and adolescents use to disclose CSA. Because children and adolescents who disclosed CSA were needed to complete the study, their sample was purposeful and non-randomized. . The authors conducted open-ended interviews with 32 females and 6 males between the ages of seven and 18 years old who were in treatment addressing being a victim of CSA at the time of the study. The participants were recruited with the help of a social worker who identified the individuals meeting the criteria that were in treatment under her care. The purpose of the study was to analyze the participants' decision-making criteria and strategies used to disclose CSA, as well as to discover significant issues involved in making the decision to disclose the abuse or not (Petronio et al., 1996).

In the interviews, participants were encouraged to describe their memories of their process of disclosure and identify feelings about the disclosure target and the type of person they would be unwilling to tell about the abuse. The interviews were analyzed using systematic thematic analysis; themes were identified according to Owen's (1984) criteria of recurrence, repetition, and forcefulness. The results were then interpreted according to Communication Management of Privacy theory, which allowed the researchers to categorize the ways in which the victims of CSA socially construct their realities regarding disclosing the abuse (Petronio et al., 1996).

Based on the results, three themes emerged for these participants regarding access rules, or the decision elements that are used to decide when to disclose, to whom 
disclosure is appropriate, and how the information should be disclosed. The three themes were tacit permission, selecting the circumstance, and incremental disclosure. Tacit permission refers to a situation in which the child discloses the abuse if he or she perceives messages from others as a request to receive information about abuse. These messages can be either verbal or non-verbal and include inquiries such as "are you ok, I am worried about you" (Petronio et al., 1996, p. 188) and instances of reciprocity in which the other person discloses abuse to the victim and the victim reciprocates with his or her personal disclosure. In either instance the participants reported perceiving support and willingness to receive information about the abuse by the disclosure target. The participants indicated that when determining an appropriate situation to disclose the abuse, they sought environments that made them feel comfortable, familiar, and provided a sense of privacy. The final theme, incremental disclosure, refers to a series of statements beginning with small amounts of vague information that increase in small increments with regard to information and intensity as each previous statement is met with perceived acceptance and positive reactions by the victim. Basically, the participants in this study reported gradually telling the source about the abuse in a sequence of statements where each statement was followed by a more revealing statement if the prior message was met with reactions that show trust and support. If the target of the disclosure was perceived to be unsupportive or unwilling to hear the sequence then the victim terminated the process of disclosure (Petronio et al., 1996).

Boundary protection, or situations in which the CSA victim elects not to disclose the abuse and privacy of the information is maintained, was found to be predicated on two criteria in this study. The first criterion, labeled target characteristics, consisted of 
two themes: distrust and responsiveness. Participants in this study reported that they would choose not to disclose the abuse to someone they did not trust. In this situation, most instances of distrust were characterized by situations in which the disclosure target would be likely to go tell others about the abuse against the victim's wishes. The second theme of responsiveness was represented by participants indicating that those they perceived as being unresponsive to the disclosure would be eliminated as potential disclosure targets. Situations in which unresponsiveness would be perceived to occur according to these participants include telling a person who has never experienced abuse, telling someone who has reacted inappropriately to previous disclosures of abuse, and those that showed an unwillingness to recognize the situation as actually occurring. Simply speaking, those that are perceived to be unsupportive and disrespectful would not be told of the abuse by these participants. The second criterion that was used by these participants was anticipated reactions. Generally, when the results of disclosing were perceived to have the possibility of being negative, the participants would choose not to disclose the abuse. Specific negative results that were perceived to possibly occur include a feeling of loss of control, or that blame would be placed on the victim. In these cases feeling in control and perceived support are keys to disclosing (Petronio et al., 1996).

Petronio and his colleagues used a purposeful sample of children and adolescents, both male and female, who disclosed abuse to discover important disclosure criteria. Although this sample size was limited based on the fact the participants were all from one area and receiving care from one specific social worker and responses were not broken down according to gender, this study still provides insight into the process of disclosure. 
In either case, with regard to permitting access or restricting access, perceived support from others was critical in the decision-making process. Support was said to be communicated if the other person asked about the welfare of the victim or used nonverbal cues that are perceived as caring, if the person disclosed abuse to the victim, or reacted positively to gradual disclosures. Settings that are comfortable and familiar were also important to these victims when choosing to disclose. It is likely that settings that meet these requirements are perceived as supportive, as well; however, further research is needed to confirm that hypothesis.

A study conducted by Foster in 2011 found similar results. Foster analyzed 21 trauma narratives that children had written as part of an intervention in therapy designed to address symptoms of Posttraumatic Stress disorder associated with being victims of child sexual abuse. The narratives the children wrote described life before, during, and after the time they were sexually abused. Eighteen females and 3 males participated in the study (Foster, 2011).

The narratives were transcribed, the content of the narratives was analyzed, and the data was analyzed to uncover themes. One meta-theme, which was titled Fear and Safety, emerged as well as several themes: Memories of the Abuse; Disclosure of the Abuse and Subsequent Events; and The Healing Journey. When focusing specifically on the theme of Disclosure and Subsequent Events, three sub-themes emerged: perceptions of the abuse disclosure, experiences during the investigation, and experiences with the justice system. When specifically considering the individuals' perceptions of the abuse disclosure, it was found that 9 of the 21 individuals said they frequently thought about disclosing the abuse to someone in hopes that it would help stop the abuse from 
continuing to occur. Many waited weeks, months, or even years to disclose the abuse, even though they wanted to tell. The individuals reported feeling afraid they would not be believed, afraid they would get in trouble, and that they were unsure what would happen next, both to them and the perpetrator. They also recalled their feelings during the disclosure process, which included fear, nervousness, and after the disclosure occurred, relief (Foster, 2011).

While these results cannot be applied to males in general, the results of Foster's study highlight feelings of fear and a need for safety associated with the decision to disclose abuse by victims of CSA. The victims in this particular study expressed being afraid of the reactions people would have if they disclosed abuse and they expressed a need for protection from the perpetrator and to feel safe, in general.

The results from the studies reviewed highlight social influences as having an impact on disclosure of sexual abuse in male victims. Specifically highlighted is the need to be believed and supported by a significant person in the victim's life (Crisma et al, 2008, Foster, 2011, Kogan, 2005, O’Leary \& Barber, 2008, Petronio et al., 1996, Sorsoli et al., 2008, Teram et al., 2006) and to feel safe and protected (Foster, 2011). Lack of perceived social support or received social support appears to hinder disclosure. Also, the male victims were influenced by society's view of male gender roles and victimization. Specifically, the view that males cannot be victims of sexual abuse hinders disclosure (Petronio et al., 1996, Sorsoli et al., 2008, Teram et al., 2006). Even though there are many barriers to disclosure, some victims of child sexual abuse do disclose the abuse. Investigating the disclosure process will provide a better understanding of what conditions are associated with disclosure. 


\section{Types of Disclosure}

According to Ullman and Filipas (2001), disclosure is the reporting of abuse to another person, and can occur in two forms: formal or informal. A formal disclosure occurs when the child tells a professional about the abuse. These professionals include medical doctors, mental health professionals, law enforcement officials, and forensic interviewers at child advocacy centers, or other professional settings. Informal disclosure occurs when the child tells a member of his or her family or social network. Recipients of informal disclosures can be parents, other relatives, teachers, and friends (Ullman \& Filipas, 2001).

Priebe and Svedin (2008) examined the types of disclosures child victims of sexual abuse make. The researchers surveyed 4,339 male and female high school seniors in Sweden. Findings indicated that victims of CSA that disclosed the abuse, seldom disclosed formally to a professional. The participants reported disclosing most often to a trusted friend. Males in the study were more likely to disclose to a friend than anyone else (Priebe \& Svedin, 2008). London et al. (2005) investigated disclosure rates of child sexual abuse, and the findings regarding teens were similar. The results revealed that $85 \%$ of victims that were sexually abused during adolescence most often disclosed to a friend of similar age at the time of abuse. London and colleagues also found that victims that were school-aged children (6-12 years old) most often disclosed to a parent at the time of abuse (London et al., 2005). The difference in recipients of disclosure for the different age groups should be taken into consideration.

These two studies provided little or no information regarding what happened after the victims of CSA disclosed to peers or parents. It is unknown whether these informal 
disclosures prompted supportive help from caregivers, mental health therapists, and a professional investigative team, or whether their efforts to receive help were met with disbelief and lack of support. Further investigation is warranted to understand the outcomes of these different types of disclosures. Also, the research provided no information as to the participants' reasons for disclosing to these particular people, and it appears as though the targets of disclosure change based on the developmental level of the victim. Examining sources of support as it relates to disclosure may provide insight into this issue.

\section{Social Support}

In general, social support refers to the assistance given to those who are coping with stress (Thoits, 1986). The social support given to an individual during the stressful time acts as a buffer to the stress, preventing the person from developing unmanageable symptoms of anxiety and depression and/or maladaptive behaviors. Thus, social support increases one's well-being in the face of stressful life events (Cohen \& Wills, 1985).

While there is agreement among psychologists regarding the general concept of social support as it has developed over time, there is disagreement about the specific elements that comprise social support. The review of the literature on social support found that the beginning of the concept of social support in psychology was associated with Rogers's (1942) client-centered therapy. Within this theory, the concept of unconditional positive regard, which is always viewing the client in a positive light, regardless of what he or she does or says, is fundamentally a social support approach. The research of Lindeman (1944) on grief management, Caplin (1964) on preventive 
community psychiatry and the importance of support groups, and Cassel (1976) on the importance of the presence of a significant other on buffering stress in both people and animals are areas in which the presence and importance of social support is highlighted. By 1976, social support was seen as the mere presence of another person or persons who viewed an individual in a positive way (Caplin, 1964; Cassel, 1976; Lindeman, 1944; Rogers, 1942).

The work of Cobb (1976) was a turning point in the development of the concept of social support. Cobb changed the idea of social support by expanding the concept from just the mere presence of another individual or individuals to the exchange of information from one individual to another who is in need. According to Cobb, there are three categories for the exchange of information in social support. The first category is emotional support, which is the belief that one is loved and cared for by another. The second category, esteem support, is the belief that one is esteemed and valued as a person by another human being. And the third category is the concept that one belongs to a network of mutual obligations and communication in which these other two concepts are conveyed. Cobb purported that these categories for exchange operate throughout the lifespan and they are the common factors in modifying the stress one experiences by increasing the coping ability of a person and facilitating adaptation in the form of selfchange to essentially improve the person-environment fit (Cobb, 1976).

In the 1980's, Hirsh and House were the next major contributors to the concept of social support. According to Hirsh (1980), social support consists of five possible elements: Emotional support, encouragement, advice, companionship, and tangible aid. Hirsh's concept of emotional support is similar to that of Cobb (1976). Hirsh (1980) 
identified encouragement as praise, compliments, and inspiration by a supporter. Advice is considered any opinion or suggestion offered by another to help an individual. The concept of companionship consists of time spent with another person and the feeling that one is not alone. Finally, tangible aid is any type of resource, such as money or assistance in completing a task such as a chore, provided by another person (Hirsh, 1980). House (1981) related social support to the world of work and identified three concepts comprising social support in the work-force The first, like in the other concepts, is emotional support. Second, House identified appraisal as an important component, stating that in the work force, one needs to have information and feedback from others that is relevant to self-evaluation. The third concept is informational. This concept encompasses suggestions, advice, and information, which are needed to perform a job successfully and feel supported (House, 1981).

Tardy (1985) developed one of the most comprehensive models that identified and defined five important aspects, or dimensions, of social support. The first dimension, referred to as direction, refers to whether social support is being given to someone else or being received from someone else by an individual. The second dimension, which is disposition, has two aspects: availability and enacted. Availability refers to the supports someone has access to, and enacted refers to the supports a person has utilized. Description/evaluation is the third dimension, and it refers to whether someone elicits an evaluation or a description of the social support. The fourth dimension is content, which has four types: emotional supports such as trust and love, instrumental supports, or resources, such as time and money, informational supports such as advice and information, and appraisal support, which is feedback given in an evaluative nature. 
Finally, the fifth dimension of Tardy's model of social support is network, which consists of the sources or people that comprise an individual's support network (Tardy, 1985).

While Tardy's (1985) model seems to be the most comprehensive definition of social support, it is not the main concept used by social scientists for social support. In fact, many attempts since the early 1980's have been made to specify the concept of social support and create one unifying description that incorporates what has been proposed previously; however, no clear consensus on a full definition has been reached. Despite this lack of clear consensus, each social support model has considerable overlap with the next, which has allowed common factors to be identified. It appears as though the common factors among social support models that exist are: emotional support, selfesteem support, and advice and/or help. Thus, giving comfort, helping one feel valued, and providing assistance and advice are important aspects of providing social support. According to Schwarzer and Leppin (1991), having social support conveys to a person that he or she is loved, cared for, and valued. When one believes he or she has adequate social support there is a perceived availability of help and support. There is an expectation that one can receive coping assistance and resources from a social support source. However, a person has to perceive an adequate amount of social support from others before he or she will seek out and attempt to utilize social support (Schwarzer \& Leppin, 1991).

\section{Social Support in the Lives of Children and Adolescents}

According to Erikson's (1950/1963) psychosocial stages of development, schoolaged children depend on their parents or caregivers more than anyone else. In most cases, these adults are the main source by which a child's needs are met. Parents and 
caregivers provide physical, emotional, social support, and safety for school-aged children. As children get older, the need for autonomy and independence increases. They begin to depend less on parents to meet specific needs. Parents are still the primary source of physical support and safety; however, adolescents begin to turn to peers and other individuals or groups to fulfill emotional and social needs (Erikson, 1950/1963).

When considering the developmental context in which children and adolescents acquire their needs, the fact that parents are the primary source of social support for school-aged children, and that same-aged peers appear to become the primary source of social support for adolescents (Barker, 2007), it is not surprising that some research has shown that school-aged children are more likely to disclose sexual abuse to parents, and adolescents are more likely to disclose to close peers (London et al., 2005; Priebe \& Svedin, 2008). However, the results of other studies have not been consistent and conclusive with regard to sources of social support. In fact there is much confusion regarding the most impactful sources of social support and the well-being of children and adolescents (Dubow \& Ullman, 1989).

There have been many problems with the research involving social support and the well-being of children and adolescents that likely contribute to inconsistent findings over time. While the definition and concept of social support began forming over 70 years ago and social support and its relationship to physical and psychological well-being in adults is a subject that has received a great amount of attention in research and literature, this subject in children and adolescents did not begin receiving attention until the 1980 's. Since then, the amount of research dedicated to exploring the relationship between social support and physical and psychological well-being in children and 
adolescents has increased drastically (e.g., Barerra, 1986, Dubow \& Ullman, 1989, and Chu, Saucier, \& Hafner, 2010). Despite this surge in attention towards social support's relationship to the well-being of children and adolescents, the research that has been done has complicated matters, to say the least. According to Dubow and Ullman (1989), even after the first decade of researching social support and children and adolescents, the results have been mixed. There has been no clear consensus as to the role social support plays in the well-being of children and adolescents and which sources are most impactful on the child or adolescent. Some research has concluded that certain sources of social support are more influential than others, such as parents and teachers, while other research is completely contradictory and concludes that sources other than parents and teachers are most important (Dubow \& Ullman, 1989). Further, Chu, Saucier, and Hafner (2010) pointed out that some research suggests that social support has a strong positive relationship with the physical and psychological well-being of children and adolescents, while other research results have not identified a significant relationship between social support and well-being (Chu, Saucier, \& Hafner, 2010).

According to multiple researchers (Barrera, 1986; Smith, Fernengel, Holcroft, Gerald, \& Marien, 1994) the problem with the inconsistency in results regarding the relationship between social support and well-being in children and adolescents is due to the fact that there is a variety of definitions of social support being utilized across studies, different measures are used to assess social support, and a wide range of outcome variables are utilized. Barrera (1986) and Dubow and Ullman (1989) further explained that social support is a construct with several dimensions and can be measured in several different ways. Thus, if researchers choose different dimensions to define the construct 
of social support that they are studying (i.e., network size, one's perception of social support available, the amount of social support one has already received, etc.), then the research inherently is different and cannot be said to be studying the same thing. This in turn makes comparing results across studies difficult (Barrera, 1986; Dubow \& Ullman, 1989).

Chu, Saucier, and Hafner (2010) set out to remove the confusion surrounding the relationship between social support and physical and psychological well-being in children and adolescents. To do so, the researchers conducted a meta-analysis of the studies previously done on social support and well-being in children and adolescents. There were five main purposes of conducting the research. The first purpose was to determine the strength and size of the mean effect size between social support and physical and psychological well-being in children and adolescents. The second purpose was to determine if social support had a stronger relationship to different categories of wellbeing compared to others (i.e. academic achievement, behavior problems, coping skills, etc.). The third was to discover if there are differences in the strength and direction among the different constructs of social support (i.e. network size, perceptions of social support, enacted social support, etc.). The fourth purpose was to discover if differences in the strength and direction of mean effect sizes differ between sources of social support such as family, close friends, peers, etc. And finally, the remaining goal of the research was to determine if age and/or gender are significant moderators of the relationship of social support and physical and psychological well-being (Chu, Saucier, \& Hafner, 2010). 
To conduct the study, Chu et al. (2010) utilized Internet databases to locate studies for a meta-analysis. They searched the keywords "social support" and for studies with participants that fit in childhood age ranges, preschool age ranges, grade school age ranges, or adolescence. Once studies had been found, other criteria had to be met for the studies to be considered for the meta-analysis. These criteria included: studies must be written in English, must be published in the United States, and must have used quantitative methods. Finally, the authors chose to include correlational studies that met the following inclusion criteria: participants were children and/or adolescents, the study was conducted in the United States, the individuals comprising the samples were not immigrants, the study had to have statistics sufficient for the authors to be able to calculate effect size of the relationship between social support and well-being, and the measures of social support were taken directly from the participants in the study and not from a parent or guardian. After all of the inclusion criteria were established, 246 published and unpublished studies were included in the meta-analysis. The authors were able to extract 901 effect sizes to use for data from the 246 studies. The sample sizes of the studies ranged from 21 to 14,211 and the ages of those children and adolescents sampled ranged from 3 to 20 years old. Of the studies utilized, only 18 measured male and female participants' association between social support and well-being separately. Only one study in the meta-analysis utilized male participants only, while 23 studies focused solely on the relationship between social support and well-being in females. Publication years ranged from 1980 to 2008 (Chu et al., 2010).

To prepare for the data analyses, Chu et al. (2010) had to first code social support measurements. The authors coded the measurements into five categories: size, or the 
number of people in one's social network or group of friends; enacted, or the measures that asked participants how much support each of them has actually received; perceived, which measures the participants' perceptions of available support that they could receive if needed; seeking, or how much participants actively seek out support from others; and other, which includes any measures that the authors of the study failed to differentiate from the other categories. Chu and colleagues then coded sources of support, and they developed four categories: family/relative support; friend support; teacher and school support; and others, which includes counselors, community members and other adults that have significant roles in the child/adolescent's life. To measure well-being, categories also had to be developed. These authors included categories of well-being previously created by Amato and Keith (1991) which are the following: academic achievement, which includes tests, grades, teacher ratings, etc.; conduct; psychological adjustment such as depression, anxiety, or happiness; self-concept, which includes selfesteem, perceived competence, and internal locus of control; and social adjustment. These authors also chose to include four of their own categories: health, which includes frequency of exercise, eating habits, and Body Mass Index (BMI); coping skills; career; and other, which includes measures such as life satisfaction, overall adaptive or maladaptive behaviors, etc. Finally, the authors identified age, gender, and publication year as three moderators to code, as well (Chu et al., 2010).

To analyze the effect sizes of the data from the studies, the researchers utilized DSTAT (Johnson, 1989), which is a computer software program that allows researchers to use meta-analysis to combine and review already existing research results (Johnson, 1989). The mean effect sizes for types of measures of social support ranged from almost 
zero (social network size) to moderate in magnitude (perceived support). The measure of perceived social support was more strongly associated with well-being in children and adolescents than any other measure of social support utilized. It should be noted that after discovering this significant difference, the authors made no attempt to control for the measure utilized in the sample of studies when examining support from different sources, across categories of outcomes of well-being, and when analyzing the other moderators (age, publication date). With regard to the categories of outcomes of wellbeing, the mean effect sizes ranged from .098 to .265 . Post hoc analyses showed that the mean effect sizes for the categories of self-concept and other were significantly stronger than all other categories, and academic achievement and coping skills were significantly weaker than all other categories. When analyzing effect sizes across sources of social support, the teacher and school personnel support source category was significantly stronger than all other sources and had a mean effect size of .209. The other category was significantly weaker than all other support source groups. To analyze age and publication year, the authors utilized these variables as continuous moderators. The analysis of the data showed a positive significant correlation between age and effect size and between publication year and effect size, indicating that the strength of the relationship between social support and well-being increases as the age of the participant increases, and that the effect sizes have increased as the years have progressed. Finally, the authors explored gender differences. The results revealed that there was a significant difference between gender, with female participants having a significantly stronger mean effect size than males, which suggests that female participants indicate a stronger 
relationship between social support and overall well-being than their male counterparts (Chu, Saucier, \& Hafner, 2010).

This study was a benefit to the research on social support in children and adolescents because it was the first attempt to combine several studies done over time and make sense of inconclusive data regarding the relationship between social support and well-being. The results of the research were beneficial in that it was shown that the measure of perceptions of social support has a significantly stronger relationship to wellbeing than other measures of social support and that with regard to sources of social support, teacher and school personnel support was significantly stronger than the other sources and the other support category was significantly weaker. Further, the research showed that age, gender, and publication year were significant moderators of social support, which indicates that as time has passed, specifically since 1980 through 2008, children and adolescents in general the relationship between social support and wellbeing has increased, and as children get older, the relationship between social support and well-being increases and that females have a significantly stronger relationship between social support and well-being than males (Chu et al., 2010).

Despite the fact that statistically significant results were found in this metaanalysis, there are several limitations. First and foremost, once the authors discovered that perception of social support was significantly stronger than all other measures of social support they neglected to control for that aspect when analyzing the rest of the results. Therefore, the results contain studies utilizing measures of social support with effect sizes ranging from near zero to less than moderate. This factor alone significantly alters the results. Essentially, the effect size shows how strong the significant difference 
is, and only moderate to high effect sizes are considered meaningful (Heppner, Wampold, \& Kivlighan, 2008). Given that many of the measures utilized in this meta-analysis had very weak relationships to well-being, the meta-analysis can only generate results that do not have strong effect sizes. If perception of social support was found to have the strongest and most significant relationship to well-being, especially compared to the other measure, then perception of social support should have been the only measure utilized. Second, a limitation of the existing literature before this point is the fact that some researchers have utilized different scales to measure social support, and some of these scales have been created without establishing their psychometric properties, so it is unknown what degree of reliability and validity the scales possess. There was no mention in this meta-analysis regarding the scales utilized in the sample of studies or if the authors were sure social support was actually being measured. This problem, if not controlled for in the meta-analysis, could have significantly altered the results, as well. After a thorough review of social support scales that exist for children and adolescents, I have found no existing scales that measure social support, or at least perceptions of social support, in children below the age of 8 (e.g., Social Support Appraisal Scale, Survey of Children's Social Support, and Student Social Support Scale). Some of the studies utilized children in preschool and the beginning of grade school, all of which would be under this age. Thus, it is possible that perceptions of social support assessed in these young children are invalid, or only partially so. Third, many pertinent details regarding the demographics of the participants in each of the studies were omitted, making interpreting the results problematic. No mention was made regarding race, socioeconomic status, relationship between the parents of the children and adolescents 
being assessed, the type of living situation the participants were in at the time of the study (i.e. living at home with both parents, living in a juvenile detention center, etc.). All of this information is necessary to draw meaningful conclusions from the study. Having this information may explain why the main effect sizes were moderate at best, or why teachers and other school officials were the strongest source of social support. Finally, it appears that females were represented in the samples significantly more than males, so it is unknown to what degree these results can be generalized to males, if at all.

\section{Implications for Future Research}

Even though there were several limitations to this meta-analysis, implications for future research can be drawn. It appears as though, based on these results, one's perception of social support available is the best measure to utilize when assessing the relationship between social support and well-being in children and adolescents. This makes sense given that once a child or adolescent encounters a stressful life event, if he or she does not perceive the availability of support and thus have access to support, his or her well-being will be in jeopardy because it is likely he or she will not seek out the support if it is not believed that available support exists. Future research would likely benefit most from utilizing a measure assessing perceptions of social support. Assessment of the relationship between social support and well-being appears to be lacking in male children and adolescents, so future research should focus on this area, as

well. Also, utilizing social support scales that have established and acceptable reliability and validity would help bring clarity to the relationship between social support and wellbeing. Finally, future research should identify and control for the demographics that were in question in the study by Chu et al., (2010). Demographic factors likely 
contribute significantly to the type, availability, and enacted social support that one has. This is especially likely given the fact that family dynamics are not consistent from one family to the next. As of 2006 , only $67 \%$ of children in the United States were living with both biological parents and the rates of single-parent households is at its highest ever (U. S. Census 2006). As these numbers change and more and more children and adolescents end up in foster care and in group homes, the sources of social support will likely change, and may shift towards those not in the immediate family.

\section{Importance of Supportive Non-Parental Adults}

Given the changes in family dynamics over time, both in terms of changing social reality in the United States and in individual families as children get older and become more independent and social outside of the home, there is an increased likelihood that children and adolescents will rely more and more on people outside of their immediate family for support. According to Sterrett, Jones, McKee, and Kincaid (2011), these Supportive Non-Parental Adults, or SNPAs, can be coaches, mentors, a neighbor, and/or adults in the extended family such as aunts and uncles, as well as teachers and school counselors. To be considered an SNPA, a child or adolescent must believe that the person, who is over the age of 18, supports and cares about him/her and will be available

when needed. Some researchers have made more of an effort to explore the relationships between support from SNPAs and children and adolescents' well-being. In 2011, Sterrett et al. recognized the need to integrate the literature already developed in this area in an effort to formulate a more comprehensive overview of the relationship between social support provided by non-parental adults and the psychosocial adjustment, or well-being, of children and adolescents (Sterrett et al., 2011). 
To investigate how the presence of SNPAs impact adolescents' psychosocial adjustment, Sterrett and colleagues (2011) integrated findings across several studies. These studies involve several types of SNPAs such as natural and formal mentors, grandparents, social networks, and kinship support, and the studies address several topics such as academic adjustment, emotional and behavioral problems, and self-esteem. Based on the results, Sterrett and colleagues found that the presence of SNPAs in the lives of adolescents is associated with higher levels of academic functioning. Adolescents who report the presence of SNPAs also report more positive attitudes about school, greater motivation to perform well in school, stronger belief in the importance of school, and these adolescents also have higher attendance rates and academic achievement than those who do not report the presence of SNPAs in their lives. The presence of SNPAs has been found to be associated with increased levels of positive behavioral outcomes and a decrease in problematic behaviors such as conduct problems, substance abuse, and sexual activity. Further, the presence of SNPAs in the lives of adolescents has also been associated with fewer emotional problems, such as symptoms of depression. With regard to self-esteem, it appears as though the association between self-esteem in adolescents and the presence of SNPAs is dependent upon the type of SNPA as well as the form of support given. For example, the authors referred to a study conducted by Vazsonyi and Snider (2008) in which it was found that early adolescents who reported higher levels of emotional and instrumental support from adult relatives had higher self-esteem and a healthier self-concept. Also, the presence of an adult co-worker at a part-time job who was available to provide instrumental support was also associated with higher levels of self-esteem (Sterrett et al., 2011). 
In exploring how the relationships between SNPAs and children/adolescents differ from the relationships between parents and children/adolescents and peers and children/adolescents, Sterrett and colleagues (2011) highlighted a study conducted by Beam, Chen, and Greenberger (2002). Based on the results of the study by Beam and colleagues (2002), the adolescents sampled indicated that SNPAs can offer advice based on life experiences that their peers are unable to give. Further, the adolescents in the study indicated that they felt more comfortable seeking advice from SNPAs instead of parents, especially on uncomfortable or embarrassing topics such as relationships and sexual activity (Beam et al., 2002).

While Sterrett and colleagues (2011) highlighted several studies that provided support for the association between the presence of SNPAs and positive academic adjustment, the absence of emotional and behavioral problems, and higher self-esteem, there were a few studies that did not provide support for these associations. The results of most of the studies that did not find the existence of this positive association suggest that certain characteristics of the SNPA, such as his or her behavior or emotional state, may be factors that negatively impact the psychosocial development of the adolescent. For example, Sterrett et al. (2011) highlighted a study conducted by Farruggia, Greenberger, Chen, and Heckhausen (2006) in which these authors found that adolescents who perceived that the very important non-parental adults in their lives were engaging in problem behaviors are more likely to exhibit higher levels of conduct problems (Farruiggia et al., 2006). Further Sterrett and colleagues (2011) referenced a study in which Chen, Greenberger, Farruggia, Bush and Dong (2003) found that SNPAs experiencing depressed mood are associated with higher levels of youth depression. 
Based on the results of these studies, it appears as though the presence of a SNPA may not be enough, and that the SNPA must also engage in appropriate behaviors and be mentally healthy in order to have a positive impact on adolescents' psychosocial development. Further, these results may indicate that children and adolescents are likely to mimic the behaviors and mental health states of those they spend time with, meaning that social support may not be a positive aspect of one's life if his or her sources of social support are not healthy people.

While Sterrett et al. (2011) were able to integrate many different studies related to different sources of SNPAs and psychosocial development in adolescents, which had not been done previously, the research conducted by these authors is severely limited. At no point in the article did the authors elaborate on the data analyses that were (or were not) utilized, thus putting into question the strength of the results they have reported. Further, the methods, measurements, and analyses utilized in the studies that were integrated into this research report were not mentioned either, which further questions the value of these results. If the studies reviewed utilized different measures of social support, or the authors of these studies created their own measures of support for the purpose of their study, then it would be hard to compare and/or integrate results in a meaningful way. This is especially true given the fact that, as mentioned previously, not many measures of social support exist for adolescents and ones that have been developed by authors specifically for their study have not been tested prior to their use to determine if adequate reliability and validity exist. Further, as Sterrett and colleagues did highlight, many of the studies that were researched did not elaborate on the details of the type of social support that was measured in the study (i.e. emotional support, instrumental support, etc.) 
and it is possible that these authors have integrated results of studies measuring different types of support. Despite these major limitations, there is evidence that support received or perceived from SNPAs is in some way associated with positive psychosocial development in the areas of academics, behavior and emotion development, and selfesteem, unless the SNPA is engaging in problematic behaviors and/or is struggling with mental health problems. However, further research is needed in this area to control for the limitations previously mentioned and to understand these associations more meaningfully, and eventually to identify the relationship between SNPAs and psychosocial development in adolescents.

Based on the available research regarding the relationship between social support and children and adolescents' well-being, not much is known, especially with regard to male children and adolescents. However, the limitations of the research done in the past do provide information as to how to conduct future research in this area. First, it is imperative to utilize a measure of social support that has adequate reliability and validity to ensure that the results are valid and can be compared to other studies. Second, it would be most beneficial, based on results of previous studies (e.g., Beam et al., 2002, Sterrett et al., 2011) to measure children and adolescents' perceptions of the social support that may be available to them. Third, it will be important to assess different sources of social support, especially with samples with diverse demographics. Lastly, it appears that previous research has focused on assessing the relationship between social support and a myriad of behaviors, aspects of psychosocial functioning, and the development of emotional and behavioral problems. It would be beneficial for researchers to focus on the relationship between perceptions of social support and the 
likelihood a child/adolescent engages in help-seeking behaviors. By focusing on finding factors that lead children and adolescents to seek social support in the midst of stressful life events, we may be able to increase the likelihood that children and adolescents receive necessary help after potentially traumatic events such as child sexual abuse.

\section{Social Support and Disclosure}

Disclosure is a healthy, help-seeking behavior for children who have been victims of sexual abuse ("Darkness to Light", 2009). However, as mentioned previously, many children do not disclose abuse or wait until adulthood to disclose the abuse. This is especially true with male CSA victims (Sorsoli et al., 2008, Tang, Freyd, \& Wang, 2007). Understanding the factors surrounding disclosures of abuse, especially with male CSA victims, will be beneficial in improving the rate of disclosure and its associated positive outcomes.

Crisma, Bascelli, Paci, and Romito (2004) explored factors associated with disclosure for adolescent victims of sexual abuse. Specifically, they interviewed these adolescents regarding their fears and needs as well as the factors impeding disclosure of the abuse. Based on the interviews several needs of the participants after the abuse occurred were identified. The majority of the participants cited the need to talk to someone that will listen, be supportive, and be non-judgmental. Participants also verbalized the need to be believed and not blamed for the abuse. If these needs were not perceived to be able to be met, then disclosure became less likely (Crisma et al.). These expressed needs suggest the importance of social support in the disclosure process. 
Further, these needs highlight the importance of perceptions of social support in the disclosure process.

Current research regarding disclosure of sexual abuse by child victims indicates that perceived social support is, in fact, an important factor for a child when determining whether or not to tell someone about being the victim of sexual abuse (Crisma et al., 2004; London et al, 2005; Priebe \& Svedin, 2008; Sorsoli et al, 2008). Disclosure for male victims of child sexual abuse appears to be especially influenced by perceived social support. The amount of social support a male expects to receive upon disclosure appears to be impacted by amount of influence society's negative view of males as victims of sexual abuse has on the particular individual targeted for support. Those individuals perceived as not being impacted by society's view of males as victims of sexual abuse will likely be viewed by the male victim as a good source of social support and be more likely to elicit a disclosure (Nagel et al., 1997; Sorsoli et al, 2008; Ullman \& Filipas, 2001).

Thus far most research regarding victims of child sexual abuse and disclosure has been qualitative in nature with the goal of understanding factors related to whether or not disclosure occurs (e.g., Crisma et al., 2004 \& Petronio et al., 1996). The literature on child sexual abuse and disclosure demonstrates the importance of perceived social support. Despite important findings, according to London, Bruck, Wright, and Ceci (2008) the previous research that was reviewed all have similar limitations that hinder what can be inferred from the results. For instance, most of the studies relied on retrospective recall to gain data, which means that the honesty of the participants and their abilities to accurately recall traumatic events is taken into question. The procedures 
by which some researchers chose to obtain samples are also a limitation. In most cases, the researchers obtained samples of male victims of CSA that had already disclosed the abuse or were willing to discuss abuse. This produces a biased sample. Unfortunately, due to the nature of CSA, this is a problem that is not easily solved. Also, the definition used for abuse has varied across studies. In some cases it has been conservative with regard to age and requirements needed to consider the act sexual abuse. The more conservative definitions used in the study hindered the researchers from identifying more instances in which males have been victims of CSA and thus affect the results of the studies (London et al., 2008).

The present study aims to establish the relationship between perceived social support and disclosure of sexual abuse by male victims, while avoiding the limitations of previous studies. By studying perceived social support of the victim at the time the victim must make a decision to disclose to a professional at a Child Advocacy Center (CAC), many of these limitations will be controlled. It is understood that using only Child Advocacy Centers as sources for participants in this study is a limitation, as it is not the only setting in which a child can disclose sexual abuse. However, given that these sites have standard procedures that each of them have developed and utilize a standard, unbiased protocol when interviewing a child or adolescent about sexual abuse, it is believed that by only conducting the research within CACs that other extraneous variables can be controlled for (i.e., way in which the child disclosed, proof that disclosure was not forced, ensuring that the child's well-being was taken into consideration, etc.). Also, to help control for limitations of previous research, a measure of perceived social support with established and adequate reliability and validity will be 
used. Based on the previous research findings, it is hypothesized that perceived social support will predict disclosure of child sexual abuse by male victims. The more social support a child perceives to have from parents or friends, the more likely the child will be to disclose sexual abuse. Given that there are mixed results regarding the sources of social support and which are most influential to adolescents, this study will aim to discover which sources, parents, teachers, close friend, or group of friends, most strongly predict disclosure of sexual abuse by male children and adolescents. It is predicted that higher levels of perceived social support will be positively related to disclosure and be negatively related to non-disclosure.

Research efforts have not yet attempted to identify perceptions of social support as a major factor effecting disclosure of CSA by male children and adolescents. This study will likely guide future research on male victims of CSA and hopefully lead to a greater understanding of factors related to disclosure. If social support is identified as a factor affecting disclosure, this study can be used as a source of education for the public at whole, especially those who frequently interact with children and adolescents on a daily basis such as parents and teachers. Further, it is possible that this study will highlight specific sources of social support and specific behaviors that convey the presence of social support that affect whether or not a male child/adolescent discloses CSA. These identified sources and behaviors will be key to utilize to help male children and adolescents perceive social support from adults in their lives so if abuse occurs they will be more likely to disclose promptly. 


\section{CHAPTER 2:}

\section{METHODS}

Four Child Advocacy Centers were used to recruit participants for the study: the Stark County Children's Network in Canton, Ohio; the Harmony House of Belmont County in Ohio; The Harmony House in Wheeling, West Virginia; and the Monongalia County Child Advocacy Center in Morgantown, West Virginia. Child Advocacy Centers (CACs) are child friendly centers for children and adolescents who have experienced abuse or are alleged victims of abuse. Each CAC hosts a multi-disciplinary team consisting of law enforcement, prosecution, child protective services, victim advocates, medical care, and mental health care that aid in supporting the victim through forensic interviews and investigations aimed at prosecuting the perpetrator of the abuse. Child Advocacy Centers in general were chosen as recruitment sites for the study because they follow a standard protocol for their forensic interview and investigative team process. This ensured that each participant went through the same procedures and was provided the same types of information and services before beginning the study. Many CACs were solicited to participate in the study; however, only the directors of these four centers agreed to allow their site to be utilized in the research study. Each director signed a letter of agreement. Please see Appendix D for a copy of the permission form.

It was important to recruit participants from CACs because they conduct Forensic Interviews with alleged victims of sexual abuse and offer these victims the opportunity to disclose the abuse. By recruiting participants and assessing their perceptions of available social support at or near the time of their Forensic Interview, we were able to be more confident of the relationship between perceptions of social support at the opportunity to 
disclose the abuse and whether or not the victim chose to disclose the abuse. Further, each CAC followed the same protocol, therefore we were able to guarantee that each victim was offered the same services, the same opportunity to disclose abuse, and were provided the same types of information for their respective investigation.

All four of the CACs use the same standard protocol that they use for every Forensic Interview. This research study did not interrupt the procedures at the Child Advocacy Centers in any way. No person associated with the CAC was active in recruiting participants or collecting data. This ensured that the flow of the interview process was not interrupted and the child or adolescent's best interest with regard to mental health, safety and the investigation of alleged abuse remained in the forefront of both the study and the investigation. From this point forward in this section, CAC will be used to refer to any or all four of the sites, as the procedures did not differ between sites. In fact, the procedure that describe below is the common and standard protocol for assessing all potential victims who are referred to a CAC.

The process for an alleged victim to have an opportunity to disclose abuse in a forensic interview begins with a referral to the CAC. Once a referral was received at the CAC, the director of the site contacts the parent or guardian of the referred male to schedule the forensic interview. At this point the parent or guardian was educated with regard to the function of the $\mathrm{CAC}$, and that a concern regarding the child or adolescent's well-being had been brought to light. The adult was also instructed not to discuss the interview or any potential abuse that may have occurred with the child or adolescent prior to arriving at the CAC. 
Upon arrival at the CAC the child or adolescent meets the certified Forensic Interviewer and spent time with him or her in the waiting room to build rapport. Efforts to build rapport include playing card games, playing with interactive toys or games, and engaging in discussions about neutral subjects. Concurrently, the parent(s) or guardian(s) escorting the individual to the interview meet in a private room with the CAC's Child Advocate. At this time they are reminded of the purpose of the interview and procedures of the CAC. They are also asked to complete background information forms (for the use of the CAC) and provide consent to interview the child or adolescent. Any questions or concerns they had are also addressed. Once informed consent to interview the child or adolescent was obtained, the child then participates in a Forensic Interview (please see Appendix E for a description of the Forensic Interview format). Each interview follows a standard format with regard to asking the child or adolescent about the abuse. While the child is being questioned regarding instances of sexual abuse, an Investigative Team consisting of a member of Law Enforcement, a Prosecuting Attorney, a case worker from Child Protective Services, and the Child Advocate views the interview from a television in a private room. During the interview the child either provides a disclosure of sexual abuse or denies the occurrence of sexual abuse, based on the definitions utilized in this research study. At the conclusion of the interview the child or adolescent is permitted to relax in the waiting room with family while the Forensic Interviewer discusses the interview with the Investigative Team and a plan of action is decided upon. At this point the Investigative Team decides whether to continue the investigation (where the assumption that the male is a victim of CSA is made) or to terminate the investigation (where the assumption that the male is not a victim of sexual abuse is made). The Family 
Advocate informs the victim and his parent(s)/guardian(s) of the Investigative Team's plan to move forward (or not) with the investigation, along with whether or not the child/adolescent disclosed abuse, and answered any questions they may have had. If the investigation was terminated the male and his family were informed that the investigation was ending, despite whether or not the child or adolescent disclosed the abuse.

\section{Participants}

During a four-month period from October 2013 to February 2014, all males between the ages of 7 and 14 years old that were referred to any of the CACs as possible victims of sexual abuse were eligible for participation in the research study. There were exclusionary criteria applied to the selection and retention process that determine whether or not a potential subject remained active in the study. These criteria were present to simplify the study and to ensure that the well-being of each child and adolescent remained the first priority. The first criterion for inclusion was disclosure. A participant remained in the study if during a forensic interview he disclosed sexual abuse or he did not disclose sexual abuse but the investigative team believed sexual abuse occurred and elected to continue the investigation. Reasons considered valid for which an investigative team would believe sexual abuse occurred without disclosure include: evidence of sexual abuse found in a medical evaluation, evidence provided by one or more witnesses, and strong belief by law enforcement that the abuse occurred. Informed consent and assent were also factors associated with participation in this study. A potential participant only remained active in the study if he, as well as a parent/guardian, agreed to participate. The time frame between when the actual abuse occurred and when the child is given the opportunity to disclose the abuse during a 
forensic interview was not a factor considered in this study because the focus of the study is on perceptions of social support at the time of disclosure.

Potential referral sources for CACs, and thus for the participants, include parents, guardians, school officials, law enforcement, child protective service workers, neighbors, extended family members, and anonymous callers. No potential participants were excluded based on factors such race, ethnicity, or socioeconomic status. During the four months of data collection, 11 males chose to participate in the study. One male participant did not complete the study fully, and therefore his information was eliminated. A total of 10 males were used as participants in the study.

\section{Measures}

For the purpose of this study, the definition of sexual abuse was all-inclusive. Sexual abuse was defined as any sexual or physical act involving genital penetration, digital penetration, fondling of genitals by either the victim or the perpetrator, viewing of pornographic materials such as pictures and videos, and/or forced participation in acts that constitute child pornography or those that would be considered acts of grooming a child for pornography. These definitions of sexual abuse are consistently and broadly used across studies and within the field. See Medline (2009) for a review of terms associated with child sexual abuse. By using the definition of disclosure, the participants were not required to disclose the type of abuse they experienced. Therefore it was assumed that if the Investigative Team of the CAC determined that abuse occurred, the type of abuse fell into one of these categories.

The definition of disclosure that was used for the study was strict. To be considered a disclosure the child or adolescent had to admit to at least one instance of 
sexual abuse as defined by this research study. Non-disclosure was defined as any denial of sexual abuse or a half-disclosure. Disclosure type was determined by each Child Advocacy Center's Forensic Team and the result of the interview (disclosure or nondisclosure) was provided to the alleged victim and family at the conclusion of the forensic interview.

An Information Sheet was used to obtain demographic information and information about the participant's life at the time the suspected abuse was to have happened. Specific information solicited from each participant included: Current Age, race/ethnicity, socioeconomic status of the victim's family, disclosure status, with whom the victim was living at the time the abuse occurred, relationship of the victim to the perpetrator, and whether or not the victim and his parent/guardian were told that the investigation of the abuse would continue. (Please see Appendix C for a copy of the Information Sheet).

The Child and Adolescent Social Support Scale (CASSS) (Malecki \& Demaray, 2002) was utilized to measure the perceived social support of the participants in the research study. The CASSS had been chosen due to the fact that it is one of the only existing social support scales for use with children. Also, the CASSS has the most applicability, as it is able to assess the broadest age-range of participants of the existing measures of social support. The CASSS was created for use with children in third grade through adolescents in their senior year of high school (Malecki \& Demaray, 2002); however, although norms have not been attained, the authors contend that the CASSS (2000) may be used on children in first and second grade. There was also no concern demonstrated by the authors regarding whether or not a participant completed the scale 
on his own or had the items read to him aloud by a researcher (C. Malecki, personal communication, July 13, 2011).

Malecki and Demaray designed the CASSS based on Tardy's (1985) model of social support, which consists of five conceptual domains: direction, disposition, description/evaluation, content and network. According to Tardy, direction refers to whether the support is given to the person by another person, or received by the person from another person. Disposition refers the availability of support versus whether the individual utilizes the support. Description refers to the details of the type of social support received and by whom it was received. Tardy contends that there are four types: emotional, instrumental, informational, and appraisal. Evaluation measures the person's satisfaction with the social support that was received. Finally, network refers to the people who provide the support (Tardy, 1985). Utilizing this conceptualization, Malecki and Demaray view social support as one's perception of supportive behaviors towards oneself, both general and specific that lead to an improvement in functioning from individuals and groups of people in a social network (Malecki, Demaray, \& Elliot, 2004).

The authors created the format of the CASSS based on the Student Social Support Scale, which was developed by Nolten (1994). The CASSS (Malecki et.al, 2004) is a 60item scale that measures perceptions of social support in children and adolescents from five sources: parent, teacher, classmate, close friend, and school. There are 12 items in each source category that address the four types of support: emotional, instrumental, informational, and appraisal. The CASSS requires the participants to rate the items according to two aspects: frequency and importance. The CASSS utilizes frequency ratings that consist of a 6-point Likert-type Scale ranging from 1 Never to 6 Always and 
importance ratings on a 3-point Likert-type Scale ranging from 1 Not Important to 3 Very Important (Malecki et al., 2002).

Malecki et al. (2002) demonstrated adequate reliability and validity of the CASSS (2000) on students from fifth to twelfth grade. While the CASSS (2000) is appropriate to use with children below fifth grade, data on children in grades below fifth is not yet available. In their research, the authors used a large sample of 1,160 students in grades three through twelve to conduct tests of reliability and validity through test-retest and correlational analyses of the scores obtained on the CASSS. The Cronbach's alpha coefficient for both Total Frequency Scale and Total Importance Scale for students in grades five through eight ranged from .96 to .97 . The alpha coefficients for the Frequency Subscales for grades 5 through 8 ranged from .92 to .96 , while the range for Importance subscales was from .88 to .95 . For students in grades 9 through 12 , the Cronbach's alpha for Total Frequency Scale was a .97 and was a .98 for the Total Importance Scale. The alpha coefficient for Frequency Subscales ranged from .90 to .95 and the range for the Importance subscales was from .89 to .96 . Test-Retest Reliability for an 8-10 week period was only available for those children in grades five through eight. The coefficients ranged from as low as $.45-.65$ on the Importance Subscales to as high as $.75-.78$ on the Total Frequency Scale. While the coefficients for the Total Frequency Scale are adequate, the coefficients for the Importance Subscales are low, indicating that the participants' ratings of the importance of each act conveying social support were not consistent over time. It was recognized at the development of this study that utilizing the Importance Subscales in this study may impact the reliability of the results to a degree. Due to the small number of participants in the study, the Importance 
Subscales were not utilized in order to reduce potential error resulting from sample size limitations.

The results also indicate that the CASSS has strong validity for the internal structure, convergent validity, and divergent validity. Validity for the internal structure of the CASSS was calculated by confirmatory factor analysis. The CASSS was found to have moderate to high intercorrelations among the subscales. Convergent validity was demonstrated with adolescents in grades nine through twelve by comparing the scores obtained on the CASSS with scores the Social Skills Subtest of the Social Skills Rating System (SSRS) and the Self-Confidence Composite of the Student Self-Concept Scale (SSCS). The correlation between the CASSS and the SSRS - Social Skills was .62 and the correlation between the CASSS and the SSCS-Self-Confidence Composite was .49 (Malecki et al., 2002).

Convergent Validity was demonstrated for children in grades five through eight by comparing scores on the CASSS with total scores from the Social Support Scale for Children (SSSC) and the Social Support Appraisals Scale (SSAS). The correlation between the CASSS and the SSSC was .56 and the correlation between the CASSS (2000) and the SSAS was .55. Correlations between the CASSS and the Personal Adjustment subscale of the Behavior Assessment Scale for Children Self Report of Personality (BASC SRP) for both groups were also assessed. Correlations between the CASSS and the BASC SRP were .36 for children in grades five through eight and .43 for adolescents in grades nine through twelve. The correlations between the CASSS and these measures are considered to be in the moderate range (Malecki et al., 2002). According to Heppner, Wampold, and Kivlighan (2008), although strong correlations are 
preferred, moderate correlations between constructs are tolerated and even expected. These correlations, indicating convergent validity between the CASSS and the SSSC, SSAS, and BASC SRP, provide evidence that the CASSS adequately measures social support (Malecki et al., 2002).

Scores on the CASSS also demonstrated divergent validity with three subscales of the BASC SRP: Clinical Maladjustment, Emotional Symptoms Index, and School Maladjustment. Correlations were calculated for both groups. For children in grades five through eight, correlations between the CASSS and the BASC SRP were as follows: Clinical Maladjustment -.20, Emotional Symptoms Index -.28, and School Maladjustment -.41. For adolescents in grades nine through twelve the correlations between the CASSS and the BASC SRP were as follows: Clinical Maladjustment -.36, Emotional Symptoms Index -.41, and School Maladjustment -.37 (Malecki et al., 2002). These negative correlations between the CASSS and the subscales of the BASC SRP are in the moderate to low range indicating that the CASSS does not measure maladjustment or the presence of unpleasant emotional symptoms. While these correlations do not make as strong of a case for the validity of the CASSS as the convergent correlations, it may be more meaningful to use these divergent correlations in conjunction with the convergent correlations. Heppner and colleagues (2008) contend that as long as the correlations of measures of different constructs are smaller than the correlations of measures of the same construct, divergent validity exists. Given that the divergent correlations for the CASSS and three subscales of the BASC-SRP are much smaller than the convergent correlations between the CASSS and the SSSC, SSAS, and BASC SRP, divergent validity exists. Also, according to these authors, there is no adequate range that has been established 
between convergent and divergent correlations to justify the validity of a measure. The only requirement is for convergent correlations to be higher than divergent correlations (Heppner et al., 2008). According to these standards, the CASSS is an adequate measure of social support in children and adolescents.

\section{Procedures}

As mentioned above, all procedures for participant recruitment and data collection were designed so that there would be no interference with standard protocol at each of the CACs. Equally as important, all procedures were designed to protect the participant and parent/guardian identity. The participants, and those that were recruited but chose not to participate, as well as their families, remained (and still remain) anonymous to the researchers and to the staff at the CACs. The only way any potential participant or actual participant/family's anonymity was to be compromised was if the participant/family chose to let their identity be known.

The first step in conducting this research project was obtaining approval from the Institutional Review Board (IRB) at West Virginia University. The researcher proposed the project to the IRB and explained the purpose of the proposed research study, the intentions of doing no harm and maintaining the best interest of the child or adolescent participant, and the procedures for obtaining informed consent and assent and observing HIPAA requirements for confidentiality of research data and personal information.

To recruit potential participants, fliers were placed on the walls of the waiting rooms at the CACs informing the males and their families of the study. By reading the fliers, people were made aware that they had an opportunity to participate in a study conducted by researchers at West Virginia University to gain information that would be 
used to ultimately help prevent child sexual abuse. On the flier it stated that the researchers were interested in learning about the beliefs male children have about the support they receive from important people in their lives. The fliers specifically stated that the researchers were recruiting male participants between the ages of 7 and 14 that recently had a forensic interview at the CAC. The readers were also informed that participation in the study would take a maximum of 30 minutes. If interested, they were instructed to take a packet that was placed below the flier. (Please see Appendix F for a copy of the flier.)

Each of the packets contained the following: an introductory letter; the information sheet; the CASSS; and a stamped and addressed envelope that would be used to mail the data to the researchers. See the appendices for samples of these documents. Each of the packets contained an arbitrarily selected identification number that would be used to identify the participant in the study. The number was located on each of the forms inside the packet.

The introductory letter served several purposes. First, it provided an introduction to the study and informed the reader that to participate in the study, the participant must be a male between the ages of 7 and 14 that completed a forensic interview at the CAC because he was suspected to be a victim of sexual abuse. By placing this information in the opening paragraph, the reader was able to discontinue reading if he did not qualify for the study. If the reader chose to continue, he was notified that the research study was not affiliated with the CAC and participation in the research study would not affect the processes, procedures, or outcomes of his case with the CAC. Next, the requirements of participating in the study were reviewed: continue reading the letter in its entirety; 
complete the information sheet; complete the CASSS; and mail the materials to the researchers. He was then informed that there likely would be no personal gain from his participation, but that his information may help identify important factors that help male children and teens disclose abuse and get the help they need. Then, the subjects of parental consent and assent were discussed. The potential participant was informed that formal consent and assent forms were not being used as they required parent and child/adolescent signatures. It was made clear that by completing the forms and mailing them to the researchers, the parent was indicating consent and the participant was indicating assent. By waiving consent and assent, we were able to maintain the participants' anonymity and no one would be able to link the participant to his sexual abuse data. The parent and participant were also informed that if they could discontinue participation at any time with no penalties or consequences. If they decided to remove their data from the study after it was mailed to the researchers, they were instructed to call the researcher and provide the identification number of their information and it would be removed. The researcher's contact information, along with the principal investigator's information and the contact information of the specific $\mathrm{CAC}$ at which the forensic interview took place was located at the end of the packet. Completed packets by willing participants were mailed to the researcher.

When the researcher received an envelope containing a completed packet it was opened and reviewed. First, the researcher would make sure the packets were completed. Then, the researcher checked the participant's response on the information sheet to the question "Were you told at the Child Advocacy Center that they would continue the investigation of this case because they believed that the suspected abuse occurred?". If 
"no" was the response circled, the data from the participant was not used in the study as this indicated that the CAC's Investigative Team did not believe the abuse occurred or did not have enough evidence to prosecute the perpetrator. If the participant responded with "yes", his data remained in the study. All eligible data, upon receipt, was entered immediately into a password protected Excel Program to eventually be used for data analysis. The identification numbers were used in the Excel Program to identify each participant's data. The packets were placed back in their respective envelopes and stored in a locked filing cabinet in the researcher's office. 


\section{CHAPTER 3:}

\section{RESULTS}

Initially, when developing the research study, the data regarding perceptions of social support obtained by utilizing the CASSS was to be analyzed using logistical regression. It was believed that logistical regression was best suited for this research study as it is used to describe the relationship between more than one independent variable and a binary response variable that has only two values. In this study, disclosure and non-disclosure were to be the binary criterion variables, while the social support scores from the five categories on the CASSS as well as the total social support score were to be the predictor variables. By utilizing logistical regression in SPSS, we would have been able to calculate regression coefficients for each predictor variable, which describe the size of its contribution to the association with the criterion variable. It was hypothesized that measured levels of perceived of social support would be positively related to disclosure and be negatively related to non-disclosure. Unfortunately, the sample size obtained for this study prevented the data from being analyzed by using logistical regression. According to Hosmer and Lemeshow (2000), in a logistic regression the minimum number of cases per independent variable is 10 , therefore a sample size of at least 50 was needed for this study with five individual predictor variables obtained from the CASS.

A total of 11 packets were mailed back to the researcher; however, one packet was left completely blank, leaving the total number of participants in the study equaling 10. The age of the participants spanned between 7 years old and 14 years old, with an average age of 10.7 years. One participant chose not to provide his age. Ninety percent 
$(n=9)$ of the males identified themselves as White and the other participant identified himself as Biracial $(n=1)$. Participant reporting of their living situation at the time the abuse occurred indicated that $90 \%$ of the males lived with at least one biological parent and the other male indicated he was living in a foster home at the time of the abuse. Reporting of household income during the time at which the alleged abuse occurred showed that $70 \%(n=7)$ of the males lived in families with $\$ 16,000$ or less per year income, $20 \%(n=2)$ lived in families with an income between $\$ 16,000-\$ 35,000$, and $10 \%(n=1)$ lived in a household with an annual income between $\$ 75,000-\$ 100,000$. Analyzing the abuse statistics revealed that, of the 10 participants, $80 \%(n=8)$ disclosed abuse during the forensic interview, while 20\% $(n=2)$ did not disclose abuse during the forensic interview. Despite two participants not disclosing the abuse, all 10 participants reported that they were informed by the CAC that their case would continue to be investigated because the investigative team believed the abuse occurred.

Regardless of disclosure status, all 10 participants identified their relationship to the alleged perpetrator. Ninety percent $(n=9)$ indicated that the alleged perpetrator was a "family member", and one male indicated that the alleged perpetrator was a "friend".

The internal consistency of the CASSS was estimated for each of the 5 categories (Parent, Teacher, Classmates, Close Friend, and School) derived from the responses by the sample used in this study. The range of responses for each item, which ask the participant how often he receives a type of social support, within each category range from 1 to 6 , where $1=$ never and $6=$ always. A total score on each scale is calculated by adding together the responses on the 12 items, with total scores ranging from 12 to 72 for each participant. The Close Friend category had the highest estimate of reliability with a 
Cronbach's alpha of $.98(M=50.80, S D=19.20)$, while the Teacher category had the lowest estimate of reliability with a Cronbach's alpha of $.86(M=58.43, S D=9.90)$. Cronbach's alpha for the Parent scale was $.95(M=53.50, S D=13.82)$. For the Classmate scale, the Cronbach's alpha was $.94(M=50.10, S D=15.37)$ and the School category had a Cronbach's alpha of .96

$(M=52.30, S D=16.92)$. Each of the reliability estimates for the 5 categories indicate a high degree of internal consistency among the items in each category of the CASSS.

The Pearson's $r$ correlation coefficient was calculated to measure the relationships between each of the categories of the CASSS. Several significant positive relationships exist between the categories. There are significant positive relationship between perceptions of social support received from Parents and perceptions of social support received from the following categories: Teacher, $r(8)=.84, p<.01$; Classmates, $r(8)=$ $.86, p<.01$; and School $r(8)=.75, p<.05$. The Teacher and Classmates categories were significantly correlated, $r=.88, p<.01$, as were the Teacher and School categories, $r=$ $.75, p<.05$. There were significant correlations between the Classmates and Close Friend categories, $r=.70, p<.05$, and between the Classmates and School categories, $r$ $=.85, p<.01$. The Close Friend and School categories were also significantly correlated, $r=.84, p<.01$. All of the aforementioned significant correlations indicate that an increase in the perceptions of social support from one of those categories would lead to an increase in the perceptions of social support from the other category. There was a nonsignificant correlation between the Close Friend and Parent categories, $r=.48, p=$ .16 , and between the Close Friend and Teacher categories, $r=.58, p=.07$. For all intercorrelations that are statistically significant, an increase in the perceptions of social 
support in one category will likely lead to an increase in the perceptions of social support in the other related category(s). Please see Table 3.1 for a summary of the findings.

Table 3.1

Intercorrelations within the Sample Among the Categories of the CASSS

\begin{tabular}{lccccc}
\hline \multicolumn{1}{c}{ Category } & Parents & Teachers & Close Friend & Classmates & School \\
Parents & - & & & \\
Teachers & $.84 * *$ & - & & \\
Close Friend & .48 & .58 &. & & \\
Classmates & $.86^{* *}$ & $.88^{* *}$ & $.70^{*}$ & - & \\
School & $.75^{*}$ & $.75^{*}$ & $.84 * *$ & $.85 * *$ & - \\
$*{ }^{*}<<.05$ & & & & & \\
$* * \mathrm{p}<.01$ & & & &
\end{tabular}

The independent samples $t$ test was used to compare the means of the category scores on the CASSS between the participants who did disclose abuse and those who did not disclose abuse. Males who disclosed abuse $(M=4.54, S D=1.24)$ and males who did not disclose abuse $(M=4.12, S D=1.00)$ did not differ significantly on their perceptions of social support from Parents, $t(8)=.435, p=.675$. The two groups, those who disclosed abuse $(M=4.90, S D=.87)$ and those who did not disclose abuse $(M=4.70, S D$ $=.88$ ), did not differ significantly on their perceptions of social support from Teachers, $t(8)=.288, p=.781$. Perceptions of social support of males who disclosed $(M=4.31, S D$ $=1.32)$ and males who did not disclose $(M=3.62, S D=1.36)$ did not differ significantly for the category of Classmates $t(8)=.657, p=.529$. The category of Close Friend showed no significant differences between the perceptions of social support of the males who disclosed abuse $(M=4.40, S D=1.62)$ and those males that did not disclose abuse 
$(M=3.58, S D=1.89), t(8)=.620, p=.553$. Similarly, the perceptions of social support of males who disclosed abuse $(M=4.58, S D=1.12)$ and males who did not disclose abuse $(M=3.45, S D=2.65)$ did not differ significantly for the category of School, $t(8)=$ $1.011, p=.342$. While the means of scores indicating the amount of social support the participants perceived that they receive from the varying sources did not differ significantly, in each instance the mean scores of the males who did disclose abuse were larger than the mean scores of the males who did not disclose abuse. Please consult Table 3.2 for a summary of the findings.

Table 3.2

Comparison of the Means of the Category Scores on the CASSS Between Participants Who Disclosed and Did Not Disclose Abuse

\begin{tabular}{lcccccc}
\hline & \multicolumn{2}{c}{ Disclosure } & \multicolumn{2}{c}{ No Disclosure } & \\
\cline { 6 - 7 } \multicolumn{1}{c}{ Category } & $M$ & $S D$ & $M$ & $S D$ & $t(8)$ & $\mathrm{p}$ \\
\hline Parent & 4.54 & 1.24 & 4.12 & 1.00 & .435 & .675 \\
Teacher & 4.90 & 0.87 & 4.70 & 0.88 & .288 & .781 \\
Close Friend & 4.40 & 1.62 & 3.58 & 1.89 & .620 & .553 \\
Classmates & 4.31 & 1.324 & 3.62 & 1.36 & .657 & .529 \\
School & 4.58 & 1.12 & 3.45 & 2.65 & 1.011 & .342 \\
\hline
\end{tabular}

Independent samples $t$ test was also used to compare the mean age of the participants who did disclose abuse with the mean age of the participants that did not disclose abuse. Of the 10 participants only 9 provided their age on the Information Sheet. No significant differences were found between the mean age of the males who 
disclosed abuse $(M=10.86, S D=3.53)$ and the mean age of the males who did not disclose abuse $(M=11.00, S D=4.24), t(7)=-0.049, p=.962$.

The chi-square test of independence was used to determine if there is a relationship between household income at the time the alleged abuse occurred and disclosure status. In the original data obtained, 7 of the males lived in families with $\$ 16,000$ or less per year income, 2 lived in families with an income between $\$ 16,000$ $\$ 35,000$, and 1 lived in a household with an annual income between $\$ 75,000-\$ 100,000$. The data were collapsed to two categories for the purpose of running this test to include 7 participants in the income category of $\$ 0-16,000$ and 3 participants in the income category of above $\$ 16,000$. There was not a significant relationship between disclosure status and household income level, $\chi(1, N=10)=1.071, p=.301$. However, it is worth noting that both males that did not disclose the abuse came from households in the lowest income level $(\$ 0-\$ 16,000)$. The chi-square test of independence was also used to determine if a relationship exists between the relationship of the abuser to the victim and disclosure status. In the original data, 7 males reported that the alleged abuser was an "Other Family Member", meaning any family member that is not a Parent or Step-Parent. Two males reported that their alleged abuser fell into the catch-all, "Other" category and 1 male reported that his alleged abuser was a "Friend". For the purpose of running this test, the data were collapsed into two categories: "Other Family Member" $(n=7)$ and "Other" $(n=3)$. There was not a significant relationship between disclosure status and the relationship of the victim to the alleged abuser, $\chi(1, N=10)=.476, p=.49$. No other categories of information obtained from the Information Sheet could be used for 
further analysis as there was not enough variability in participant responses. Please consult Table 3.3 and Table 3.4 for a summary of the findings.

Table 3.3

Relationship Between Household Income at the Time of Abuse and Disclosure Status

\begin{tabular}{cccc}
\hline & Income $\$ 0-16,000$ & Income $\$ 16-35,000$ & Total \\
\hline Disclose & 5 & 3 & $\mathbf{8}$ \\
$\begin{array}{c}\text { Did Not } \\
\text { Disclose }\end{array}$ & 2 & 0 & $\mathbf{2}$ \\
Total & $\mathbf{7}$ & $\mathbf{3}$ & $\mathbf{1 0}$ \\
$\begin{array}{c}\text { Pearson Chi- } \\
\text { Square }\end{array}$ & Value $=1.701$ & $\mathrm{df}=1$ & $p=.301$ \\
\hline
\end{tabular}

Table 3.4

Relationship Between The Relationship of the Abuser to the Victim and Disclosure Status

\begin{tabular}{cccc}
\hline & Other Family Mem. & Other & Total \\
\hline Disclose & 6 & 2 & $\mathbf{8}$ \\
Did Not & 1 & 1 & $\mathbf{2}$ \\
$\begin{array}{c}\text { Disclose } \\
\text { Total }\end{array}$ & $\mathbf{7}$ & $\mathbf{3}$ & $\mathbf{1 0}$ \\
$\begin{array}{c}\text { Pearson Chi- } \\
\text { Square }\end{array}$ & Value $=.476$ & $\mathrm{df}=1$ & $p=.490$ \\
\hline
\end{tabular}




\section{CHAPTER 4:}

\section{DISCUSSION}

Until this study was developed, research efforts had not yet attempted to identify perceptions of social support as a major factor affecting disclosure by male children and adolescents of child sexual abuse (CSA). The purpose of this study was to establish the relationship between perceived social support and disclosure of sexual abuse by male victims. It was predicted that higher levels of perceived social support would be positively related to disclosure and be negatively related to non-disclosure.

Unfortunately, the sample size obtained prevented the intended data analyses of logistical regression to be completed. No statistically significant data regarding the relationship of perceived social support to disclosure was obtained from the analyses that were performed. However, some meaningful non-statistical information was gathered from the study, which can be used to guide future research in this area, and the information gathered does provide motivation to duplicate this study on a larger scale.

\section{Participants}

Seventy-two participants were required to run logistical regression to determine if perceptions of social support predict disclosure of CSA by male victims. This participant requirement was based on the five CASSS subscales, the Total Support score and the Importance scores for each Subscale and the Total Importance score. Over the course of 4 months, only 10 participants were recruited and returned completed packets for this research study. Of the 10 participants, 9 were White and 1 participant indicated that he was Biracial. As mentioned previously, the small sample size hindered analyzing the data obtained in the way originally intended. The sample that was obtained is not 
representative of the larger population and, therefore, even if any statistically significant results had been obtained, could not be generalized to the greater population.

Three main factors can likely be attributed to obtaining a small, predominantly White sample. First, the sample size obtained was dependent on the number of referrals obtained by the CACs participating in the study over the four-month data collection period. It is possible that the sites did not receive many referrals for male CSA victims fitting the specific criteria for participation in the research. In fact, the Director of one of the CACs did state that they did not receive any referrals for male CSA victims during that time period. Second, the sample obtained is limited by whether or not the investigative teams determine that, to the best of their knowledge, the abuse that is being investigated actually occurred. So, even if a potential male participant was referred to the $\mathrm{CAC}$ for a Forensic Interview during that time, he may not have been eligible for the study based on the results of the Forensic Interview and the decision of the Investigative team. Third, three of the CACs participating in the research are located in predominantly White areas. Only the Children's Network of Stark County, Ohio is located in an inner-city area in which a more ethnically diverse population can be found. It would be beneficial for future research to recruit participants from CACs in several regions around the country.

\section{Disclosure Rate}

The disclosure rate of the participants in this study was high compared to retrospective studies that have found that male CSA is underreported and many male victims never disclose abuse (Sorsoli et al., 2008, Tang, Freyd, \& Wang, 2007). Of the 10 participants in the study $80 \%$ disclosed abuse, while only $20 \%$ did not disclose abuse. 
One explanation for the high disclosure rate for the participants may be that more awareness of the occurrence of child sexual abuse is being brought to the public eye, conveying that victims will be believed, accepted, and helped if they disclose, making it appear safer than once believed for male children to disclose abuse. Another explanation for the higher disclosure rates is that the participants in this study had the opportunity to disclose during a Forensic Interview at a Child Advocacy Center (CAC). These are child-friendly, unbiased interviews that are intended to provide a warm and accepting environment for the child victim to tell his abuse story. Retrospective studies conducted with adult males who were CSA victims revealed that many of the males never disclosed the abuse for fear they would not be believed and or supported (Sorsoli et al., 2008). The CAC and the Forensic Interview may have helped the child to feel safe and supported and this increased the likelihood that he would disclose abuse. Further, the male participant was already a suspected victim of sexual abuse before the Forensic Interview, or else he would not have been referred for an interview at the CAC, so it is possible that he may have already disclosed or partially disclosed the sexual abuse to a source outside of the CAC. It is possible that the population of males that are referred to the $\mathrm{CAC}$ for a Forensic Interview is biased towards individuals that are likely to disclose the abuse.

\section{Demographic Variables Affecting Disclosure Status}

Demographic information was gathered on each participant. Unfortunately, based on participants' reports, there was not enough variability in the Race/Ethnicity statistics or the participants' living situations at the time the abuse occurred. Nine of the 10 males were White, while only 1 was Biracial. Nine of the 10 males lived with at least 1 
biological parent at the time the abuse occurred, while 1 lived in a foster home at the time of abuse.

The mean age of the participants who did disclose abuse and who did not disclose abuse were compared. No significant differences in the means of the ages were found, indicating that age of the participant did not affect disclosure.

Household income at the time of the abuse was a factor with enough variability among the participants that for statistical analysis; however, disclosure status did not vary significantly as a function of household income at the time of abuse. It is worthy of noting that the two males that did not disclose abuse were from a household with a yearly income of $\$ 16,000$ or less. It is possible that socioeconomic status influences disclosure status as males from the lowest socioeconomic status did not disclose abuse; however, there were not enough participants in this study to find statistical significance. A review of the available literature on male CSA found no studies that focused on the relationship of socioeconomic status to disclosure status. Further exploration of the effect of household income on disclosure status is warranted.

The relationship of the alleged abuser to the male victim was also a factor with enough variability among the participants that to allow quantitative analysis. Disclosure status did not vary significantly as a function of the relationship of the abuser to the victim. Based on this study alone, the relationship of the abuser to the victim does not affect whether or not the male victim discloses abuse; however, this data would have to be analyzed on a much larger scale with a sample that is generalizable to the larger population of male victims of sexual abuse to produce meaningful results. 


\section{Perceptions of Social Support and Disclosure}

The Child and Adolescent Social Support Scale (CASSS) demonstrated to be an adequate measure of perceptions of social support for the participants. Each of the reliability estimates for the five categories indicated a high degree of internal consistency among the items in each category (Parent, Teacher, Close Friend, Classmates, School). The items reflect each category based on the data from the 10 participants.

When comparing the relationship of the five categories of the CASSS to each other, each category, with the exception of the Close Friend category, was positively related to each of the other categories. The Close Friend category was strongly related to only Classmates and School. For the categories that are positively related to each other, an increase in perceptions of social support of one category would lead to an increase in the perceptions of social support in the other category. It makes sense that the Close Friend category is only strongly related to Classmates and School and not the Parent and Teacher categories. Developmentally, as children get older, their focus of social support shifts from the adults in their life (parents and caretakers) to their same-age peers. As they enter adolescence, same-age peers become the most important source of social support (Barker, 2007; Erikson, 1950/1963).

The means of the category scores on the CASSS between the participants who did disclose abuse and those who did not disclose abuse were compared. While there were no significant differences in the means for each category, it is worth noting that in every instance, the means of the scores in each category for those individuals who disclosed abuse were higher than the scores of those individuals that did not disclose abuse. All of the means, from those individuals that did disclose abuse and those that did not disclose 
abuse, were on the higher end (all above 3.4) of the 6-point Likert scale. This suggests that these participants all perceive that they receive a high amount of social support from Parents, Teachers, Classmates, Close Friends, and School. This is what would be predicted based on the fact that all but 2 participants disclosed abuse. It is possible that with a larger number of participants these results could attain statistical significance. Further exploration in this area is also warranted.

\section{Strengths}

This research was designed to account for several of the shortcomings of the previous research on male CSA victims. One of the major strengths of this research study was that it focused solely on male CSA victims. The majority of the research studies involving male victims of CSA also used female participants and combined the data obtained by both males and females when conducting analyses and reporting results. This left any findings from the research unable to be generalized to the male population. By focusing solely on males, this study was able to provide information to help further research and education about male victims of CSA. Another shortcoming of previous research is that most of the previous research relied on adult participants' retrospective recollection of the abuse suffered as a child and the disclosure (or lack of) process. Because these studies were conducted several years, sometimes decades, after the fact, the accuracy of the participants' recollections and their honesty in reporting the events is questioned. To control for this shortcoming, the data about the abuse, the disclosure, and the perceptions of social support were collected at the time of the participants' Forensic Interviews. By providing the opportunity to participate in the research the same day the male CSA victim had a Forensic Interview, concerns regarding a person's ability to 
recollect facts was minimized. Also, because of the standard protocol that CACs follow and the services that they provide, participants were afforded the opportunity to ask the Family Advocate of the CAC questions about their case and Forensic Interview at any time. Therefore, if there was a specific piece of information that they could not remember, they were able to ask and be provided an accurate answer. Yet another shortcoming of previous research that was controlled for in this study was the fact that previous research studies often produced a biased sample. This is because the researchers recruited participants that had already disclosed abuse or were willing to openly discuss the sexual abuse they experienced as a child. Those individuals who did not disclose abuse, despite actually being a victim of CSA, were not included in the studies. By recruiting both male CSA victims who disclosed abuse and did not disclose abuse, equal opportunity for participation for those that disclosed abuse and those that did not disclose was assured. Finally, the other main shortcoming of previous research addressed in the present study was the inconsistent definition of sexual abuse used across studies. Studies in the past have either used a conservative definition for sexual abuse or the definition has just been inconsistent across studies. This study used a definition for sexual abuse that was all-inclusive and consistent with the legal definition for sexual abuse of a child. This allowed the study to provide data that can be applied to every type of sexual abuse, controlling for another limitation common in prior research.

The fact that the study was designed to maintain the anonymity of the participants is a major strength of this research. This was an extremely important aspect of the research study as maintaining the safety and well-being of the participants was at the forefront of the design. When addressing child sexual abuse with victims, they are being 
asked about an extremely sensitive, even traumatic topic. The fact that this research was addressing the topic of sexual abuse with the victims at the time when they were provided an opportunity to disclose the abuse they suffered makes the situation even more sensitive and potentially traumatic. By allowing the participant (and his family/guardians) to remain anonymous, a layer of safety was provided for the victim and removed the pressure of choosing whether to participate or not. By the way the design was constructed, meaning participant recruitment, waiving consent and assent, utilizing personal identification numbers, allowing the participants to remove themselves from the study at any time, and having no affiliation with the CAC's Investigative Team or outcomes of the investigation, the participants were able to maintain full control and power over their participation (or decision not to).

Finally, the method utilized to collect the data was a particular strength of this study. First, it allowed the researchers to control for the aforementioned shortcomings of previous studies. It also allowed the participants to maintain anonymity and be protected as much as possible from any harm. Equally important, participants were recruited from CACs without interfering with the CAC protocol or the Investigative Team's decisions and investigation. The fact that the CACs utilize a standard protocol allowed the researchers to trust that the participants' processes and services received at the CAC were standard and uniform for their specific abuse situations. Because the CAC provides the victim and family/guardian accurate information regarding the Forensic Interview, remains in consistent contact with the victims, and is always willing to answer questions, the participants could be assured that they would not have to interact one-on-one with another stranger (unless they choose to do so by calling the researchers) with whom they 
would have to provide private and potentially traumatic information regarding their abuse scenario.

\section{Limitations}

The major weakness of this study was the low number of male CSA victims that chose to participate in the study. As mentioned above at the beginning of this chapter, the small sample size had a negative effect on the data analysis and played a large part in the inability to obtain statistically significant findings that could be meaningfully applied to the general population of male CSA victims. Instead of revisiting previously mentioned shortcomings of this study, I will discuss the weaknesses in the research design that will hopefully be addressed and controlled for in future research in order to gain more meaningful data.

One of the biggest challenges in this study was getting CACs to help with the data collection phase of the study by allowing the researchers to recruit potential participants at their site. CACs were recruited in several areas that included: Pittsburgh, Pennsylvania; Columbus, Ohio; Clarksburg, West Virginia; Fairmont, West Virginia; and Louisville, Kentucky. All of the sites declined, with the exception of the four that took part in the study. One CAC originally agreed to help recruit participants, and later did not respond to the investigator's attempts to begin the data collection process. The directors of two sites stated that they did not believe they would be able to provide many participants, and therefore declined. Other sites never responded to the researcher's initial attempts to contact them. The sites that participated limited the diversity of the participants. For this particular study, time and money were factors that limited recruiting more CACs from several different regions of the country. Future research 
would benefit from utilizing many CACs from several areas of the country in order to obtain a sample that is more representative of the general population. Even if only a few participants are recruited from each site, the total sample size would still be large enough to conduct more meaningful statistical analyses.

It was mentioned previously that using the CACs to recruit participants was a strength of the study; however, it was also a weakness. There are several ways in which a CSA victim can disclose abuse; a CAC is not necessary. By limiting recruitment to CACs the researchers were unable to obtain participants from the other places in which children disclose abuse, such as hospitals, police stations, and therapy offices. Further, only using CACs also hindered the data collection because the overall availability of potential participants was dependent upon the number of referrals the CAC received during the data collection phase. Unfortunately, this factor is out of any one's control and cannot be predicted when conducting this type of research. However, it is suggested that more time be taken for the data collection process when using CACs in the future to maximize the likelihood of obtaining an adequate sample size.

Finally, some smaller factors may have been limitations for this study. West Virginia University's IRB restricted the use of the CAC staff for notifying the participants of the opportunity to take part in the study unless they were students of West Virginia University and/or willing to participate in an on-line research training. Because it was highly unlikely that CAC staff would be willing to take time out of their busy schedules to complete any training and be an active recruiter in the study, fliers were used to notify potential participants of the study. Only a small, standard $8 \times 11$ piece of paper was used for the flier to recruit participants. Not much color was used and the print was 
not extremely large. Only one flier was placed in the waiting room of the CAC, and none were placed anywhere else. It may not have been noticeable to the potential participants, especially if they did not spend much time in the waiting room. It may have been more beneficial to place several fliers around the CAC, such as one in the bathroom or in a meeting room, so potential participants would be more likely to become aware of the study. Also, no benefits were offered for participating in the study. Children and adolescents are often motivated by external rewards, and may have been more likely to participate if they were able to receive a concrete rewards. They were notified that their participation would help increase education and research in the area of male CSA and ultimately help prevent it from happening in the future; however, this may have been too abstract to motivate them to engage in the study. Finally, because anonymity of participants was maintained throughout the research, the accuracy of the responses on the Information Sheet and CASSS could not be verified. It is possible that the participants could have misrepresented the data to inflate their scores, or make them seem lower than what they actually are. It is believed though, that any person that would take the time to complete the packet and mail it to the researcher, was likely being honest as they were willing to help prevent the abuse that occurred to them from happening to others.

\section{Conclusions}

While no statistically significant results were found from this particular study, it did provide enough information to warrant further exploration of the relationship between social support and disclosure status and the relationship between disclosure status and socioeconomic status. Most importantly, this research demonstrated that it is possible to conduct research solely on male victims of CSA at or around the time they were 
victimized. By using CACs to recruit participants, several factors such as participant safety and control, anonymity, and the recollection of information about the abuse and disclosure status can be controlled for. Future research should attempt to recruit participants from several different CACs in several different regions of the country and plan to collect data for a longer time period.

Lastly, given how little is known about male victims of child sexual abuse, any information that leads to an increased understanding of this population is welcome. In this study I also gained an increased appreciation for the challenges faced by researchers investigating child sexual abuse, particularly among males. Since the number of male victims is compelling, the strengths and limitations of this study can serve as a guide to improve future research designs that might eventually help clinicians, family members, law enforcement, and educators provide increased and improved support for male victims of child sexual abuse. 


\section{REFERENCES}

Barker, G. (2007). Adolescents, social support and help seeking behaviour: An internationalliterature review and programme consultation with recommandations for action. WorldHealth Organization, 1-56.

Barrera, M., Jr. (1986). Distinctions between social support concepts, measures, and models. American Journal of Community Psychology, 14, 413-445.

Beam, M. R., Chen, C., \& Greenberger, E. (2002). The nature of adolescents' relationships with their "very important" non-parental adults. American Journal of Community Psychology,30, 305-325. doi: 10.1023/A:1014641213440.

Brannon, J. M. \& Larson, B. (1991). Peer counseling strategies: Facilitating selfdisclosure among sexually victimized juvenile offenders. Journal of Addictions and OffenderCounseling, 11, 51-60.

Cassel, J. (1976). The contribution of the social environment to host resistance. American Journal of Epidemiology, 104, 107-123.

Chen, C., Greenberger, E., Farruggia, S., Bush, K., \& Dong, Q. (2003). Beyond parents and peers: The role of important non-parental adults (VIPS) in adolescent development in China and the United States. Psychology in the Schools, 40, 3550. doi:10.1002/pits.10068

Chu, P. S., Saucier, D. A., \& Hafner, E. (2010). Meta-analysis of the relationships between

social support and well-being in children and adolescents. Journal of Social and Clinical Psychology, 29, 624-645.

Cohen, J. A., \& Mannarino, A. P. (1998). Interventions for sexually abused children: Initial treatment outcome findings. Child Maltreatment, 3, 17-26.

Cohen, S. and Wills, T. A. (1985). Stress, social support, and the buffering hypothesis. Psychological Bulletin, 98, 310-357.

Crisma, M., Bascelli, E., Paci, D., \& Romito, P. (2004). Adolescents who experienced sexual abuse: Fears, needs, and impediments to disclosure. Child Abuse and Neglect, 28, 1035-1048.

Darkness to Light: Confronting Child Sexual Abuse with Courage. (2009). Retrieved from http://www.darkness2light.org/

Dubow, E. F. and Ullman, D. G. (1989). Assessing social support in elementary school children:The survey of children's social support. Journal of Clinical Child Psychology, 18, 52-64. 
Easton, S. D., Coohey, C., O’Leary, P., Zhang, Y., \& Hua, L. (2011). The effect of childhood sexual abuse on psychosexual functioning during adulthood. Journal of Family Violence, 26, 41-50. doi: 10.1007/s10896-010-9340-6

Erikson, E. H. (1950/1963). Childhood and society ( $2^{\text {nd }}$ ed.). New York: Norton.

Farruggia, S. P., Greenberger, E., Chen, C., \& Heckhausen, J. (2006). Perceived social environment and adolescents' well-being and adjustment: Comparing a foster care sample with a matched sample. Journal of Youth and Adolescence, 35, 349-358. doi: 10.1007/s10964-006-9029-6.

Faul, F., Erdfelder, E., Buchner, A., \& Lang, A. G. (2009). Statistical power analyses using G*Power 3.1: Tests for correlation and regression analyses. Behavior Research Methods, 41, 1149-1160.

Foster, J. M. (2011). Foster, J. M. (2011). An analysis of trauma narratives: Perceptions of children on the experience of sexual abuse (Unpublished doctoral dissertation). University of Central Florida, Orlando, Florida.

Garnefski, N. \& Arends, E. (1998). Sexual abuse and adolescent maladjustment: Differences between male and female victims. Journal of Adolescence, 21, 99107.

Groth, N. \& Longo, R. (1982). The sexual assault of males: Victim and offender issues. Fourth National Conference and Workshops on Sexual Aggression. Denver, CO.

Hecht, M., Foster, S. H., Dunn, D. H., Williams, J. K., Anderson, D. R., \& Pulbratek, D. (1986). Nonverbal behavior of young abused and neglected children. Communication Education, 35, 134-142.

Heppner, P. P, Wampold, B. E., \& Kivlighan, D. M. (2008). Research design in counseling ( $3^{\text {rd }}$ ed.). California: Thomson Brooks/Cole.

Hosmer, D. W. \& Lemeshow, S. (2000). Applied logistic regression ( $2^{\text {nd }}$ ed.). New York: Wiley Interscience.

Johnson, B. (1989). DSTAT: Software for the meta-analytic review of research literature. Hillsdale, NJ: Erlbaum.

Kogan, S. M. (2005). The role of disclosing child sexual abuse on adolescent adjustment and revictimization. Journal of Child Sexual Abuse, 14, 25-40.

Lab, D. D., \& Moore, E. (2005). Prevalence and denial of sexual abuse in a male psychiatric inpatient population. Journal of Traumatic Stress, 18, 323-330. doi: 10.1002/jts.20036.

Levesque, R. (2007) SPSS programming and data management: A guide for SPSS and SAS users $\left(4^{\text {th }}\right.$ ed.). SPSS Inc., Chicago Ill. 
Lippert, T., Cross, T. P, Jones, L., \& Walsh, W. (2009). Telling interviewers about sexual abuse: Predictors of child disclosure at forensic interviews. Child Maltreatment, 14, 100-113. Retrieved from psycARTICLES on September 10, 2009.

London, K., Bruck, M., Ceci, S. J., \& Shuman, D. W. (2005). Disclosure of child sexual abuse: What does the research tell us about the ways that children tell? Psychology, Public Policy, and Law, 11, 194-226.

London, K., Bruck, M., Wright, D. B., \& Ceci, S. J. (2008). Review of the contemporary literature on how children report sexual abuse to others: Findings, methodolocial issues, and implications for forensic interviews. Memory, 16, 29-47.

Long, J. S. (1997). Regression models for categorical and limited dependent variables. Thousand Oaks: CA: Sage Publications.

Malecki, C. K. \& Demaray, M. K. (2002). Measuring perceived social support: Development of the Child and Adolescent Social Support Scale. Psychology in the Schools, 39, 1-18.

Malecki, C. K., Demaray, M. K., \& Elliot S. N. (2004). A Working Manual on the Development of the Child and Adolescent Social Support Scale (2000).

Medline: Child Sexual Abuse. (2009). Retrieved from www.hlm.nih.gov/medlineplus/childsexualabuse.html.

Mendel, M. P. (1995). The male survivor: Impact of sexual abuse. Thousand Oaks, CA: Sage Publications, Inc.

Nagel, D. E., Putnam, F. W., \& Noll, J. G. (1997). Disclosure patterns of sexual abuse and psychological functioning at a 1-year follow-up. Child Abuse and Neglect, 21, 137-147.

O’Leary, P. J., \& Barber, J. (2008). Gender differences in silencing following childhood sexual abuse. Journal of Child Sexual Abuse, 17, 133-143.

Owen, W. F. (1984). Interpretive themes in relational communication. Quarterly Journal of Speech, 70, 274-287.

Petronio, S., Reeder, H. M., Hecht, M. L., \& Ros-Mendosa, T. M. (1996). Disclosure of sexual abuse by children and adolescents. Journal of Applied Communication Research, 24, 181-199.

Priebe, G., \& Svedin, C. G. (2008). Child sexual abuse is largely hidden from the adult society: An epidemiological study of adolescents' disclosures. Child Abuse and Neglect, 32, 1095-1108.

Reinhart, M. A. (1987). Sexually abused boys. Child Abuse and Neglect, 11, 229-235. Retrieved from psycARTICLES on August 29, 2009.

Rogers, C. (1942). Counseling and Psychotherapy. Boston: Houghton Mifflin. 
Schwarzer, R., \& Leppin, A. (1991). Social support and health: A theoretical and empirical overview. Journal of Social and Personal Relationships, 8, 99-127.

Smith, C., Fernengel, K., Holcroft, C., Gerald, K., \& Marien, L. (1994). Meta-analysis of the associations between social support and health outcomes. Annals of Behavioral Medicine, 16, 352-362.

Sorsoli, L., Kia-Keating, M., \& Grossman, F. K. (2008). "I keep that hush-hush: Male survivors of sexual abuse and the challenges of disclosure. Journal of Counseling Psychology, 55, 333-345.

Sterrett, E. M., Jones, D. J., McKee, L. G., \& Kincaid, C. (2011). Supportive nonparental adults and adolescent psychosocial functioning: Using social support as a theoretical framework. American Journal of Community Psychology, 48, 284-295. doi: 10.1007/s10464-011-9429-y.

Tang, S. S., Freyd, J. J. \& Wang, M. (2007). What do we know about gender in the disclosure of child sexual abuse? Journal of Psychological Trauma, 6, 1-26.

Tardy, C. H. (1985). Social support measurement. American Journal of Community Psychology, 13, 187-202.

Teram, E., Stalker, C., Horery, A, Schachter, C., \& Lasiuk, C. (2006). Towards malecentric communication: Sensitizing health professionals to the reality of male CSA survivors. Mental Health Nursing, 27, 499-517. DOI: 10.1080/0161284060059994.

Thoits, P. A. (1986). Social support as coping assistance. Journal of Consultation in Clinical Psychology, 54, 416-423.

Ullman, S. E. (2007). Relationship to perpetrator, disclosure, social reactions, and ptsd symptoms in child sexual abuse survivors. Journal of Child Sexual Abuse, 16, 1935. doi: 10.1300/J070v16n01_02

Ullman, S., \& Filipas, T. (2001). Correlates of support seeking. Journal of Interpersonal Violence, 1028-1046.

Vazsonyi, A. T., \& Snider, J. B. (2008). Mentoring, competencies, and adjustment in adolescents: American part-time employment and European apprenticeships. International Journal of Behavioral Development, 32, 46-55. doi: $10.1177 / 0165025407084051$.

Vaux, A., Phillips, J., Holley, L., Thompson, B., Williams, D., \& Stewart, D. (1986). The social support appraisals (SSA) scale: Studies of reliability and validity. American Journal of Community Psychology, 14, 195-219. 


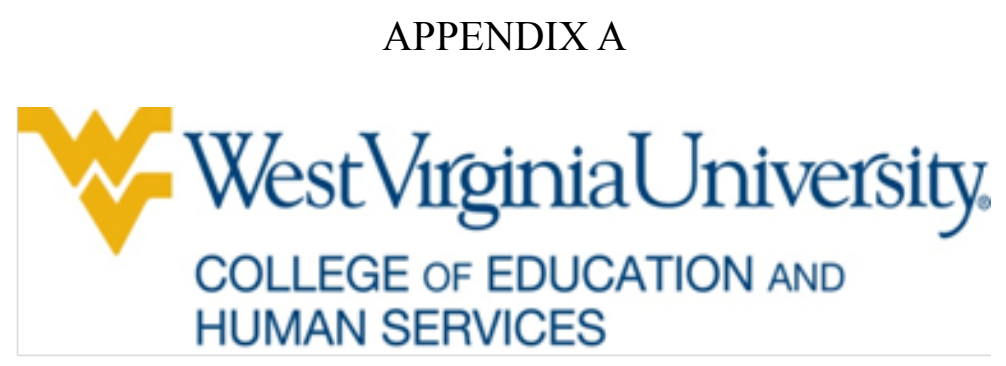

Dear Potential Participant and Parent/Guardian:

Thank you for taking the time to consider being a part of our research study! We are researchers in the Counseling Psychology Department at West Virginia University and are interested in knowing more about the opinions that male children and teens have about the available social support in their life. We are looking for male children and teens between the ages of 7 and 14 years old that have had a forensic interview at child advocacy centers. Specifically, we are looking for males that have been suspected to be victims of sexual abuse. If you or your child meets this description, please keep reading! If not, no need to read further, but thank you for your time and consideration!

To be a part of this study, all that we ask is that the child or teen participant complete a data sheet and a short social support questionnaire known as the Child and Adolescent Social Support Scale. A parent or guardian may help the participant in completing these items. Once the forms are completed, we ask that you mail them to the Co-Investigator. An addressed and stamped envelope is provided. We estimate that the total time it will take to participate in the study is no more than 30 minutes.

Protecting your child's identity is of utmost importance to us and we have taken measures to assure that his participation will remain anonymous. The researchers will not even know who he is. Also, participation is voluntary, and your child may stop participating in this study at any time. He may even remove his information from the study after he mails it to the researchers. Each packet is provided an identification code. This code is located in the top left of the data sheet and the Child and Adolescent Social Support Scale. If you or your child decides that you no longer want to participate and you have already mailed in the packet, all you have to do is call the researchers (Contact information provided at the end) and provide them with the identification code and they will remove the information from the study. Finally, in order to maintain privacy and confidentiality, we are not using parent consent forms or children's assent forms. If this packet is completed and mailed to the researchers, then you as the parent are indicating permission for your child to participate, and the child is giving permission for the researchers to use the information he provided in the study. This helps ensure that no names are linked to the information provided.

Before you agree to be a part of this study, you should know that there is no major personal benefit to participating. However, the information you provide may help the researchers learn more about social support in the eyes of male children who have been 
potential victims of sexual abuse. You may be helping to identify important factors that lead male children and teens to tell someone and get the help they need when they have been sexually abused. You may also help the researchers know what kinds of social support are important for a male child to receive so that we can help parents, teachers, and therapists create a supportive environment where a child believes he is cared for. This study is a major step in helping male children tell their stories, get the help they need, and stop keeping their abuse a secret. It is the first step in preventing child abuse.

Even though your participation in this study will be so helpful and important, there is a possibility that the participant may be harmed. It is possible that, if your child does not believe he is supported by the important people in his life, he will become upset as a result of completing the Child and Adolescent Social Support Scale. Please note that if this occurs, the Child Advocacy Center (contact information is listed at the end) is available to help address any emotional discomfort that your child may be experiencing.

Thank you for your time and consideration!

Abigail L. Leslie

Please see the next sheet for a review of this information and contact information. 


\section{Helpful Reminders}

This research is not being done on behalf of this agency. It is being conducted for the West Virginia University Researchers. You may choose not to participate and the agency will not be affected in any way, nor will your relationship with the agency.

Participation is voluntary. You may quit at any time, even after you mail the packet to the researchers.

Your identity is private and protected. The researchers will not even know who the person is that completed the information packet.

The Identification Code links you to your information (in case you want to quit). Please remember the information code. You just need to call the researchers and tell them to remove your information.

By completing the Information Sheet and the Child and Adolescent Social Support Scale and mailing it in, the parent/guardian is indicating that they are allowing the child/teen to participate and the child/teen is indicating that they are willingly participating.

This will likely take no longer than 30 minutes.

The Child Advocacy Center is available if you or your child become upset from completing this study.

\section{Contact Information}

If you have questions about the study, please contact the researcher listed below:

Researcher's Name: Abigail Leslie

Office Address: 2913 D Parklane St. NW

Canton, $\mathrm{OH} 44709$

Telephone Number: (412) 477-9269

If you would like to contact the Principal Investigator for this study, please use the following information:

Principal Investigator: Dr. James Bartee

Office Address: $\quad$ Department of Counseling Psychology

P.O. Box 6122

Morgantown, WV 26506

Phone Number: $\quad$ (304) 293-2227

This research has been approved by the Internal Review Board at West Virginia

University. If you have questions regarding your child's rights as a research subject, you may contact them Monday through Friday between 9am and 5pm at:

IRB Office 
886 Chestnut Ridge Road

P.O. Box 6845

Morgantown, WV 26506

If you believe you need assistance from a mental health professional, please contact the Child Advocacy Center.

Monongalia County Child Advocacy Center 909 Greenbag Road

Morgantown, WV 26501

(304) 598-0344 


\section{APPENDIX B}

CHILD AND ADOLESCENT SOCIAL SUPPORT SCALE - CASSS Grades 3-12

Christine Kenes Malecki Michelle Kibatrick Demaray, and Stephen N. Ewott

NAWE

TEACHER:

AGE: SCHOOL:

MALE or F BdALE (circle one)

DATE:

RACE (circle one)

1 -African American

2-Asian American

3-White

4 - Hispanic American

5-Native American

6-Other

Onthe next three pages, you will be asked to respond to sentences about some form of support or help that you might get from either a parent, a teacher, a classmate, a close friend, or people in your school. Read each sentence carefully and respond to them honestly. There gre no right or wong answers.

For each sertence you are asked to provide two responses. First, rate how often you receive the support described and then rate how important the support is to you. Below is an example. Please read it carefully before starting your own raings.

\begin{tabular}{|c|c|c|}
\hline & HOW OFIEll? & MMPQBIALLL. \\
\hline & 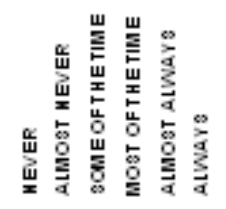 & 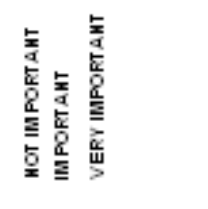 \\
\hline My teacher(s) helps me solve problems. & $12(3) 45$ & $12)_{3}$ \\
\hline
\end{tabular}

In this example, the student describes her teacher helps me solve problems' as something that happens 'some of the time' and that is 'important' to her.

Please ask for help if you have a qpestion or dont understand something. Do notskin anv sentences. Please turn to the next page and answer the cpestions. Thank you! 


\begin{tabular}{|c|c|c|c|c|}
\hline & & My Parer & 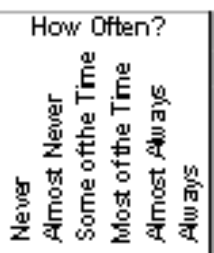 & 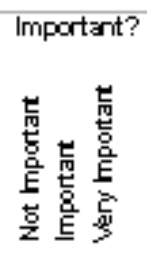 \\
\hline 可 & A I I & My Parent(s)... & & \\
\hline & & 1. ...showthey are proud of me. & \begin{tabular}{llllll|}
1 & 2 & 3 & 4 & 5 & 6 \\
\end{tabular} & 123 \\
\hline & & 2. ... understand me. & \begin{tabular}{llllll|}
1 & 2 & 3 & 4 & 5 & 6
\end{tabular} & 123 \\
\hline & & 3. ... listen to me when I need to talk. & \begin{tabular}{llllll|}
1 & 2 & 3 & 4 & 5 & 6
\end{tabular} & 123 \\
\hline & & 4. ... make suggestions when I don't knowhat to do. & \begin{tabular}{llllll|}
1 & 2 & 3 & 4 & 5 & 6
\end{tabular} & 123 \\
\hline & & 5. ... give me good advice. & \begin{tabular}{llllll|}
1 & 2 & 3 & 4 & 5 & 6
\end{tabular} & 123 \\
\hline & & 6. ... help me solve problems by giving me information. & \begin{tabular}{llllll|}
1 & 2 & 3 & 4 & 5 & 6 \\
\end{tabular} & 123 \\
\hline & & 7 .... tell me I did a good job when I do something well. & \begin{tabular}{llllll|}
1 & 2 & 3 & 4 & 5 & 6
\end{tabular} & 123 \\
\hline & & 8. ... nicely tell me when I make mistakes. & \begin{tabular}{llllll|}
1 & 2 & 3 & 4 & 5 & 6
\end{tabular} & 123 \\
\hline & & 9.... reward me when l've done something well. & \begin{tabular}{llllll|}
1 & 2 & 3 & 4 & 5 & 6 \\
\end{tabular} & 123 \\
\hline & & 10.... help me practice my activities. & \begin{tabular}{lllllll|}
1 & 2 & 3 & 4 & 5 & 6
\end{tabular} & 123 \\
\hline & & 11 .... take time to help me decide things. & \begin{tabular}{llllll|}
1 & 2 & 3 & 4 & 5 & 6
\end{tabular} & 123 \\
\hline & & $12 . .$. get me many of the things I need. & \begin{tabular}{llllll|}
1 & 2 & 3 & 4 & 5 & 6
\end{tabular} & 123 \\
\hline & & & 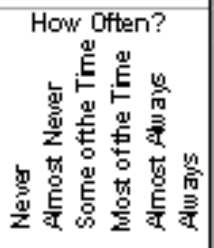 & 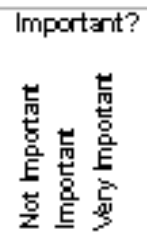 \\
\hline 81 & A 1 & My Teacher (s)... & & \\
\hline & & 13.... cares about me. & \begin{tabular}{llllll|}
1 & 2 & 3 & 4 & 5 & 6
\end{tabular} & 123 \\
\hline & & 14....treas me farly. & \begin{tabular}{llllll|}
1 & 2 & 3 & 4 & 5 & 6
\end{tabular} & 123 \\
\hline & & 15.... makes it okay to ask questions. & \begin{tabular}{llllll|}
1 & 2 & 3 & 4 & 5 & 6 \\
\end{tabular} & 123 \\
\hline & & 16.... explainsthings that I don't understand. & \begin{tabular}{llllll|}
1 & 2 & 3 & 4 & 5 & 6
\end{tabular} & 123 \\
\hline & & $17 . .$. shows me how to do things. & \begin{tabular}{llllll|}
1 & 2 & 3 & 4 & 5 & 6
\end{tabular} & 123 \\
\hline & & $\begin{array}{l}\text { 18... helps me solve problems by giving me } \\
\text { intormation. }\end{array}$ & \begin{tabular}{llllll|l}
1 & 2 & 3 & 4 & 5 & 6
\end{tabular} & 123 \\
\hline & & $\begin{array}{l}\text { 19. ... tells me I did a good job when l've done } \\
\text { somethung well. }\end{array}$ & 12234456 & 123 \\
\hline & & $20 . .$. nicely tells me when I make mistakes. & \begin{tabular}{lllllll|}
1 & 2 & 3 & 4 & 5 & 6 \\
\end{tabular} & 123 \\
\hline & & 21 .... tells me how well I do on tasks. & \begin{tabular}{llllll|}
1 & 2 & 3 & 4 & 5 & 6
\end{tabular} & 123 \\
\hline & & 22. ... makes sure I have what I need for school. & \begin{tabular}{llllll|}
1 & 2 & 3 & 4 & 5 & 6
\end{tabular} & 123 \\
\hline & & 23.... takes time to help me learn to do something well. & \begin{tabular}{llllll|}
1 & 2 & 3 & 4 & 5 & 6
\end{tabular} & 123 \\
\hline & & 24.... spends time with me when I need help. & \begin{tabular}{llllll|}
1 & 2 & 3 & 4 & 5 & 6
\end{tabular} & 123 \\
\hline
\end{tabular}




\begin{tabular}{|c|c|c|c|c|}
\hline & & assh & 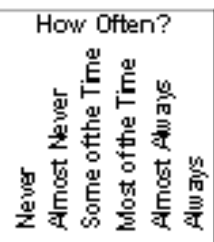 & 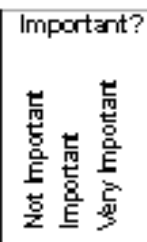 \\
\hline 目 & A 1 & My Classmates... & & \\
\hline & & $25 . .$. treat me nicely. & \begin{tabular}{llllll|}
1 & 2 & 3 & 4 & 5 & 6 \\
\end{tabular} & $\begin{array}{|lll|}1 & 2 & 3 \\
\end{array}$ \\
\hline & & $26 . .$. like most of my ideas and opinions. & \begin{tabular}{llllll|}
1 & 2 & 3 & 4 & 5 & 6
\end{tabular} & $\begin{array}{|lll|}1 & 2 & 3 \\
\end{array}$ \\
\hline & & $27 . .$. pay attention to me. & \begin{tabular}{llllll|}
1 & 2 & 3 & 4 & 5 & 6
\end{tabular} & $\begin{array}{|lll|}1 & 2 & 3 \\
\end{array}$ \\
\hline & & 28.... give me ideas when I don't know what to do. & \begin{tabular}{llllll|}
1 & 2 & 3 & 4 & 5 & 6 \\
\end{tabular} & $\begin{array}{|lll|}1 & 2 & 3 \\
\end{array}$ \\
\hline & & $29 . .$. give me information so I can lean new things. & \begin{tabular}{llllll|} 
& 2 & 3 & 4 & 5 & 6
\end{tabular} & $\begin{array}{|lll|}1 & 2 & 3 \\
\end{array}$ \\
\hline & & $30 . .$. give me good advice. & \begin{tabular}{llllll|} 
& 2 & 3 & 4 & 5 & 6
\end{tabular} & $\begin{array}{|lll|}1 & 2 & 3 \\
\end{array}$ \\
\hline & & $\begin{array}{l}31 \text {.... tell me I did a dood iob when I've done somethind } \\
\text { well. }\end{array}$ & $\begin{array}{llllll}1 & 2 & 3 & 4 & 0 & 6\end{array}$ & $\begin{array}{lll}1 & 2 & 3\end{array}$ \\
\hline & & $32 . .$. nicely tell me when I make mistakes. & $\begin{array}{lllllll} & 2 & 3 & 4 & 5 & 6\end{array}$ & \begin{tabular}{lll|}
1 & 2 & 3
\end{tabular} \\
\hline & & 33. ... notice when I have worked hard. & \begin{tabular}{llllll|}
1 & 2 & 3 & 4 & 5 & 6 \\
\end{tabular} & $\begin{array}{|lll|}1 & 2 & 3 \\
\end{array}$ \\
\hline & & $34 . .$. ask me to join activities. & \begin{tabular}{llllll|} 
& 2 & 3 & 4 & 5 & 6
\end{tabular} & \begin{tabular}{lll|}
1 & 2 & 3
\end{tabular} \\
\hline & & 35... spend time doing things with me. & \begin{tabular}{llllll|}
1 & 2 & 3 & 4 & 5 & 6
\end{tabular} & $\begin{array}{lll}12 & 3\end{array}$ \\
\hline & & $36 . .$. help me with projects in class. & $\begin{array}{llllll} & 2 & 3 & 4 & 5 & 6\end{array}$ & \begin{tabular}{lll|}
1 & 2 & 3
\end{tabular} \\
\hline & & & 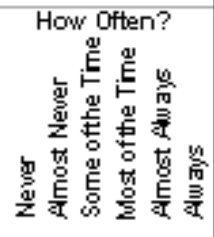 & 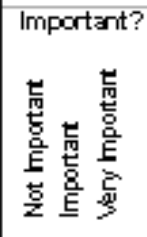 \\
\hline 目 & A 1 & MyClose Friend... & & \\
\hline & & $37 . .$. under stands my feelings. & $\begin{array}{lllllll}1 & 2 & 3 & 4 & 5 & 6\end{array}$ & $\begin{array}{|lll|}1 & 2 & 3\end{array}$ \\
\hline & & 38... sticks up for me if others are treating me badky. & \begin{tabular}{llllll|}
1 & 2 & 3 & 4 & 5 & 6 \\
\end{tabular} & $\begin{array}{|lll|}1 & 2 & 3 \\
\end{array}$ \\
\hline & & $39 . .$. helps me when l'm lonely. & \begin{tabular}{llllll|} 
& 2 & 3 & 4 & 5 & 6
\end{tabular} & \begin{tabular}{lll|}
1 & 2 & 3
\end{tabular} \\
\hline & & $40 . .$. gives me ideas when I don't know what to do. & \begin{tabular}{llllll|}
1 & 2 & 3 & 4 & 5 & 6 \\
\end{tabular} & $\begin{array}{|lll|}1 & 2 & 3 \\
\end{array}$ \\
\hline & & $41 . .$. gives me good advice. & \begin{tabular}{llllll|} 
& 2 & 3 & 4 & 5 & 6
\end{tabular} & \begin{tabular}{lll|}
1 & 2 & 3
\end{tabular} \\
\hline & & $42 . .$. explains things that I don't understand. & \begin{tabular}{llllll|} 
& 2 & 3 & 4 & 5 & 6 \\
\end{tabular} & $\begin{array}{|lll|}1 & 2 & 3 \\
\end{array}$ \\
\hline & & 43....tells me he or she likes what I do. & \begin{tabular}{llllll|} 
& 2 & 3 & 4 & 5 & 6
\end{tabular} & $\begin{array}{|lll|}1 & 2 & 3 \\
\end{array}$ \\
\hline & & 44. ... nicely tells me when I make mistakes. & \begin{tabular}{llllll|} 
& 2 & 3 & 4 & 5 & 6
\end{tabular} & $\begin{array}{|lll|}1 & 2 & 3\end{array}$ \\
\hline & & 45.... nicely tells me the truth about how I do on things. & \begin{tabular}{llllll|}
1 & 2 & 3 & 4 & 5 & 6 \\
\end{tabular} & $\begin{array}{|lll|}1 & 2 & 3 \\
\end{array}$ \\
\hline & & $46 . .$. helps me when I need it. & \begin{tabular}{llllll|} 
& 2 & 3 & 4 & 5 & 6
\end{tabular} & $\begin{array}{|lll|}1 & 2 & 3 \\
\end{array}$ \\
\hline & & $47 . .$. shares his $\alpha$ her things with me. & \begin{tabular}{llllll|}
1 & 2 & 3 & 4 & 5 & 6
\end{tabular} & $\begin{array}{|lll|}1 & 2 & 3 \\
\end{array}$ \\
\hline & & 48.... takes time to help me solve my problems. & $\begin{array}{lllllll} & 2 & 3 & 4 & 5 & 6\end{array}$ & $\begin{array}{|lll|}1 & 2 & 3 \\
\end{array}$ \\
\hline
\end{tabular}




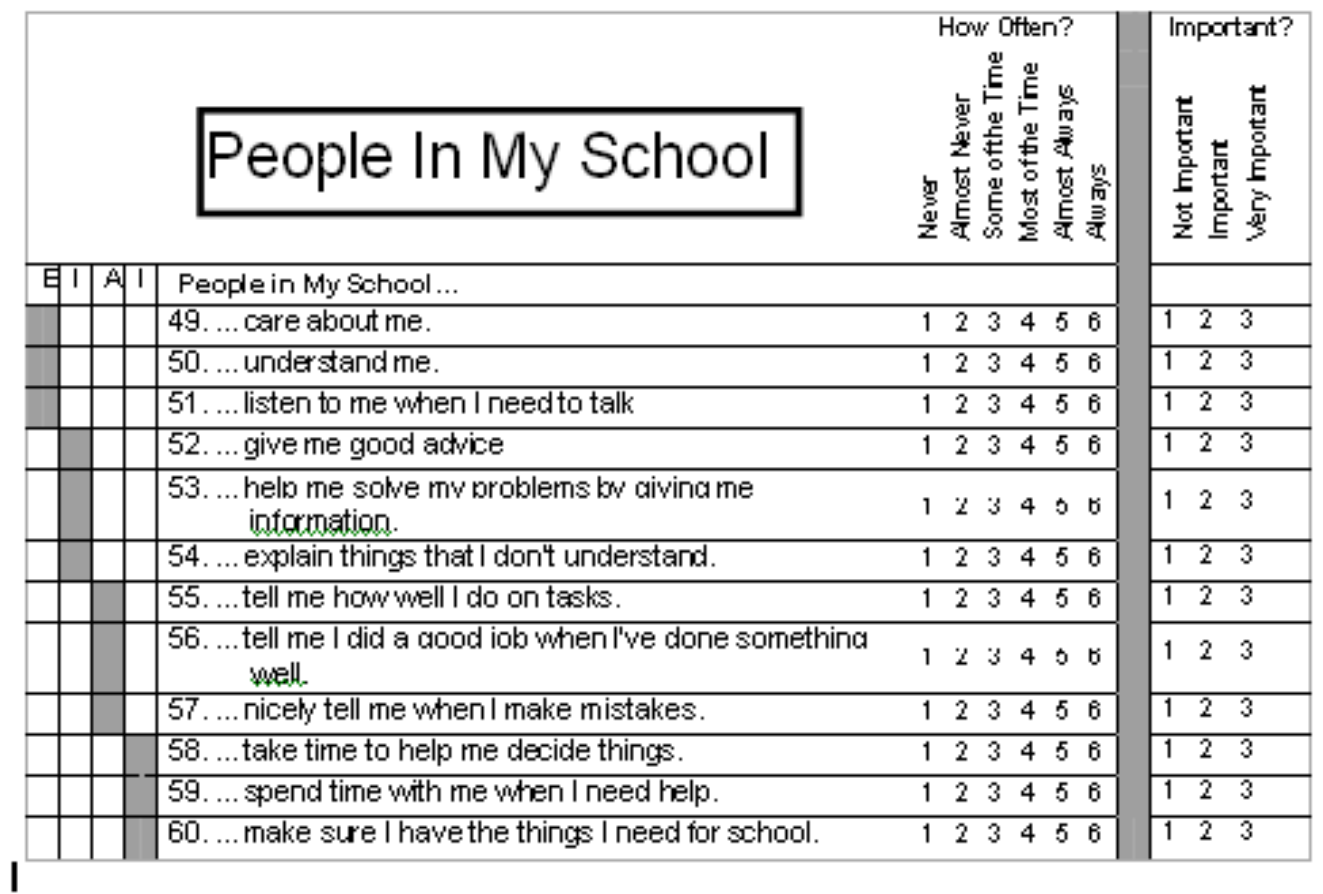




\section{West VirginiaUniversity. \\ COLLEGE OF EDUCATION AND \\ HUMAN SERVICES}

ID: $\mathbf{x x x x}$

\section{Information Sheet}

Parent/Guardian and Child:

Please complete the information below about the child's life at the time the suspected abuse was to have happened. This form may be completed by either the child or the parent/guardian. Please feel free to contact the researchers (contact information provided in the cover letter) with any questions. Do not forget to write down your ID number, which is located at the top left of this page. You will need it if you choose to stop participating in this study after you mail the information to the researchers.

Age of Child/Teen at time of suspected/reported abuse:

$\begin{array}{lrrr}\begin{array}{l}\text { Race/Ethnicity: } \\ \text { (Circle all that apply) }\end{array} & \text { African American } & \text { Latin American/Hispanic } & \text { White } \\ & \text { Biracial Asian American } & \text { Native American } & \text { Other }\end{array}$

Circle One: I IID Disclose/Tell About Abuse I DID NOT Disclose/Tell About Abuse

Were you told at the Child Advocacy Center that they would continue the investigation of this case because they believe that the suspected abuse occurred? (Circle One)

Yes No 
Who you were living with at the time of the suspected abuse (Circle One or respond in the "Other" Section):
Parents
Foster Home
Adoptive Parents
With Relatives

Group Home

Friends

Other:

Which one best describes how you know the suspected abuser (Circle One)?

The suspected abuser is my: Parent Step-Parent TeacherFriend
Stranger
Other Family Member
Other:

Circle which best describes the total yearly income level of the people in the home you were in at the time of the suspected abuse:

$\begin{array}{cr}\$ 0-16,000 & \$ 16,001-35,000 \\ \$ 75,001-100,000 & \$ 100,000 \text { and above }\end{array}$


Appendix D

\section{Letter of Consent to Participate On-Site}

$\mathrm{I}$, give permission for Abigail L. Leslie of West Virginia University's Cousenling Psychology Program to collect research data from male children and adolescents that undergo Forensic Interviews at this site for the six month timespan beginning and ending on

Executive Director 
Appendix E

Sample Forensic Interview Questions following RATAC Protocol

Introduction Statement:

"Do you know why you are here today? Well, children/teens just like you come and talk to me all the time. We talk about your family, what you like to do for fun, where you live, body parts, touches that you get, and all kinds of things. Most importantly, we talk about things that really happened".

Transition to Rapport: "When I first meet kids I like to draw a picture of their face. Will you help me draw a picture of you?" (child helps interviewer draw picture)

- Sample Questions: Where do you live - in a house, apartment, trailer, or something else?

- Who lives with you?

- Is there anyone else in your life that you think is important for me to know about?

Transition to Anatomy: "When I talk to kids about their lives, I also talk to them about body parts." (Shows child picture of a naked boy and girl)

- Sample Questions: Which one of these is a boy? Which is a girl? Which looks more like you?

- What do you call this part? And this? (Asks child to name the body parts, including the private parts, to understand the child's names for each part and to use the child's words throughout the interview to prevent confusion. Also helps child develop a sense of comfort in talking about private parts)

Transition to Touch: "When I talk to kids about body parts, I also like to talk to them about touches."

- Sample Questions: Are there any touches you get that you like? (May follow with: Some kids say they like to get hugs/kisses/high-fives)

- Who gives you touches that you like?

- Do you ever get touches that you don't like? (May follow up with: Some kids say they don't like to get kicks, punches, bites)

- Who gives you touches that you don't like?

- Sometimes kids tell me that someone has touched their private parts, has this happened to you? (Ask follow up questions: Has anyone asked you to see their private parts? Has anyone asked to see your private parts? Has anyone touched your private parts? Etc.)

Abuse Scenario: If abuse is reported, use questioning to get as much detail as possible.

- Sample Questions: Where were you when this happened?

- Did anyone see it?

- Did (the perpetrator) say anything?

- What did you see/smell/taste?

- Did this happen one time or more than one time? 
- Has anyone else ever (sexually abused) you? (this allows for alternative hypothesis testing)

Closure: Check for physical abuse, drug use in home, etc. Review safety, and what to do if this situation happens again. 
Appendix F

\section{WestVirginiaUniversity.}

COLLEGE OF EDUCATION AND

HUMAN SERVICES

\section{HELP US MAKE A DIFFERENCE}

\section{Let's Work Together to Prevent Child Abuse}

Researchers at West Virginia University understand how important it is to protect our children from abuse, especially sexual abuse. A first step in protecting children from abuse is increased understanding.

We want to understand how children/teens perceive the support they receive from important people around the time they are interviewed at Child Advocacy Centers.

If you or your child fit the following description, then you are able to help us!

\section{WE NEED:}

\section{Male children and teens Between the ages of 7 to 14 years old Who have had an Investigative (Forensic) Interview at the Child Advocacy Center}

If you are interested, please consider taking a packet below and donating less than 30 minutes of your time to complete our questionnaire about sources of support that you may receive from people in your life like teachers, friends, and caregivers. We will also ask a few questions about the Forensic Interview. We really appreciate all of your help!

This research has been approved by the Institutional Review Board of West Virginia University 
Questions? Contact the Principal Investigator - Dr. James Bartee at 304-293-2227. 
